\title{
The importance of water structure and catalyst-electrolyte interface on the design of water splitting catalysts
}

\author{
Ronguang Zhang, ${ }^{1,2}$ Paul E. Pearce, ${ }^{1,2,3}$ Yan Duan, ${ }^{1,3,4,5}$ Nicolas Dubouis, ${ }^{1,2,3}$ Thomas Marchandier ${ }^{1,2,3}$ \\ and Alexis Grimaud**1,2,3 \\ ${ }^{1}$ Chimie du Solide et de l'Energie, UMR 8260, Collège de France, 75231, Paris Cedex 05, France \\ ${ }^{2}$ Réseau sur le Stockage Electrochimique de l'Energie (RS2E), CNRS FR 3459,33 rue Saint Leu, 80039, Amiens Cedex, \\ France \\ ${ }^{3}$ Sorbonne Université, Paris, France \\ ${ }^{4}$ School of Materials Science and Engineering, Nanyang Technological University, Singapore 639798, Singapore \\ ${ }^{5}$ Energy Research Institute @ NTU, ERI@N, Interdisciplinary Graduate School, Nanyang Technological University, Singa- \\ pore 639798, Singapore
}

*Correspondance to: alexis.grimaud@ college-de-france.fr

\begin{abstract}
Hydrogen production technologies have attracted intensive attention for their potential to cope with future challenges related to renewable energy storage and conversion. However, the significant kinetic barriers associated with the oxygen evolution reaction (OER), one of the two half reactions at the heart of water electrolysis, greatly hinder the sustainable production of hydrogen at a large scale. A wide variety of materials have thus been designed and explored as OER catalysts. In this perspective, we briefly review the development of Ir-based OER catalysts in acidic conditions and discuss the limitations of a design strategy solely based on the physical and electronic properties of OER catalysts, highlighting the importance of understanding the catalystelectrolyte interface which affects the stability and activity of the catalyst. We then share our perspective on a group of crystalline, bulk protonated iridates obtained via cation exchange in acidic solutions to be used as promising stable and active OER catalysts. Finally, we discuss the advances recently made in understanding the impact of the active sites environment on the OER kinetics, emphasizing the influence of the water structure and/or solvation properties of ions in the electrolyte. We highlight the importance of developing a better understanding of these influencing factors and incorporate them into our design of OER catalysts with enhanced properties.
\end{abstract}

\section{Introduction}

Driven by the growing demand for storing and converting renewable energies in the form of electricity, recent years have seen a boom in the design of materials with enhanced electrochemical properties. This is especially true for both half reactions at the heart of water splitting, namely the oxygen evolution reaction (OER) and the hydrogen evolution reaction (HER). Hence, a wide variety of materials have been recently developed and their electrocatalytic performances toward OER and HER investigated in order to achieve hydrogen production at large scale. ${ }^{1}$ Nevertheless, while the development of materials for other electrochemical energy storage and conversion devices such as Li-ion batteries has long thrived thanks to the early understanding of the bulk properties required for the development of better electrodes ${ }^{2-6}$, predicting surface properties to guide the design of novel materials for water electrolysis has always been a challenge. ${ }^{7-12}$

Attempts to rationalize the performances of water splitting catalysts were historically rooted in the correlation existing between surface physical properties of solids and the energetics of the intermediate species, such as $* \mathrm{O}, * \mathrm{OH}$ and $* \mathrm{OOH}$ intermediates that govern the OER kinetics, for instance. ${ }^{1314}$ Pioneering works were first devoted to the study of the elec- tronic properties of the so-called dimensionally stable anodes (DSA) for the OER. ${ }^{15}$ While initially ill-understood, the field rapidly expanded and the first physical descriptors controlling the OER kinetics on the surface of transition metal oxides were proposed by Trasatti. ${ }^{16}$ Significant efforts have since then been devoted to refine these descriptors and it is now commonly accepted that by increasing the electronegativity of the transition metal ${ }^{17-19}$ which lowers the Fermi level and reduces the charge transfer energy ${ }^{20}$, an enhancement of the OER performances of transition metal oxides is observed. Similarly, the design of HER catalysts has also greatly benefited from the development of descriptors such as the hydrogen binding energy, ${ }^{10-12}$ helping uncovering a wide variety of early transition metal sulfides, phosphides or carbides as efficient and cost-effective HER catalysts to replace the state-of-the-art catalysts, e.g. platinum. ${ }^{21}$

In the last decade, we have thus seen the partitioning of research efforts in the field of electrocatalysis between materials-oriented studies encompassing the development of new water splitting catalysts guided by the use of physical descriptors, and more fundamental studies focusing on the interplay between the double layer structure and the catalytic properties of well-defined surfaces such as $\mathrm{Pt}$ or $\mathrm{IrO}_{2}{ }^{22,23}$ Never- 
theless, the recent realization that boosting the performances of OER catalysts is accompanied by drastic surface instabilities highlights the limited accuracy of these descriptors in their powers to capture the electrocatalytic stability of the best OER catalysts. ${ }^{17,18,24,25}$ The discovery of electrocatalysts that exhibit not only active but also stable catalytic performances thus currently suffers from our general lack of understanding on how surfaces interact with their environment, more precisely, on how solvent-adsorbate or other weak interactions in the interfacial water structure affect the activity and stability of electrocatalysts $^{26}$ (Figure 1). One can therefore anticipate the growing need to integrate relevant concepts including dissolution/precipitation equilibrium, hydrogen bonding network and the structure of the double layer on the surface of transition metal oxides into the design of new active and stable OER catalysts.

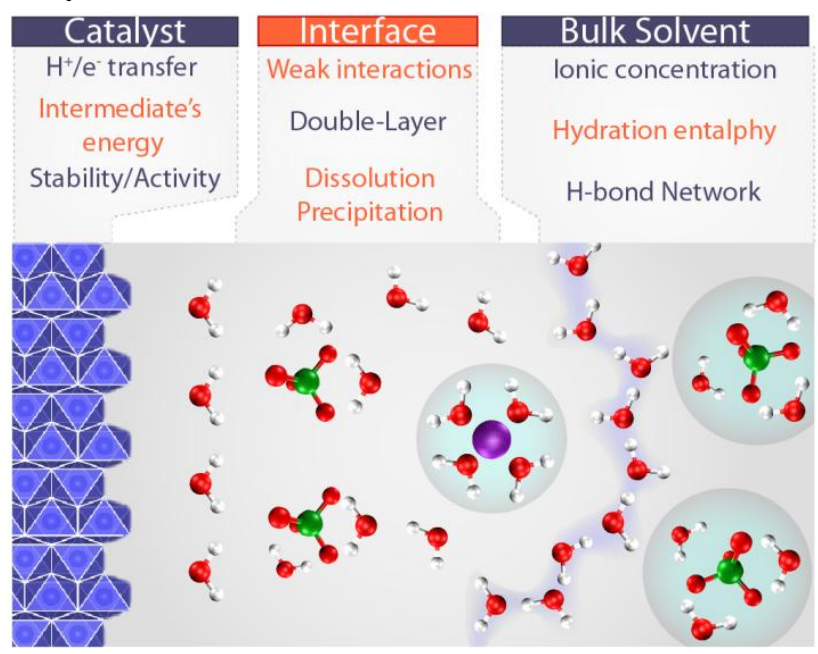

Figure 1. Electrochemical interfaces and potential research focuses for water splitting electrocatalysts.

In this perspective, we thus aim at providing a framework of different research aspects inherent to the design of OER catalysts. We will first give a brief overview on the recent development of complex iridium-based oxides as OER catalysts under acidic conditions. Through that example, we will then discuss limitations inherent to a strategy solely based on the design of materials in vacuo and highlight the complex equilibrium governing the electrocatalytic activity as well as the stability of these iridium-based catalysts under the harsh acidic conditions. This will lead us to discuss the complexity of the interactions taking place on the surface of the catalyst as well as the importance of "spectator" ions in the OER kinetics, before to focus on the physical origin for the ions dependence of the OER activity of solid catalysts recently observed for a large variety of materials.

Development of complex iridium oxides as OER catalysts in acidic media

One of the greatest challenges in the exploration of state-ofart OER catalysts lies in the unfortunate correlation existing between the enhanced OER activity and the limited stability of the catalysts. Recognizing that limitation, research efforts have recently intensified to develop strategies to circumvent this issue. Among them, promising attempts were made to limit the dissolution of transition metal cations by using nanoporous catalysts, ${ }^{27}$ by engineering the substrates/catalyst interactions to enhance the catalyst's stability, ${ }^{28,29}$ by tuning the composition of buffer-containing electrolytes to ensure the re- deposition of transition metal cations following a so-called self-healing process ${ }^{30,31}$ or by stabilizing $\mathrm{MnO}_{2}{ }^{32,33}$. These approaches bring in phenomena occurring at the electrochemical interfaces into the design of effective OER catalysts, pointing out the need to understand and control the solid-solution equilibrium at the electric double layer in order to develop better performing catalysts. One example that highlights such a realization is the development of iridium-based oxides as OER catalysts in acidic conditions.

While most transition metal complex oxides are relatively insoluble in alkaline conditions and readily precipitates as hydroxides, ${ }^{34-40}$ only iridium and ruthenium oxides are sufficiently stable in acidic conditions, with ruthenium-based oxides being more active but less stable than their iridium counterparts. ${ }^{41}$ Therefore, numerous studies were devoted to the development of iridium-oxides as OER catalysts in acidic environment. Thermally prepared stoichiometric $\mathrm{IrO}_{2}$ is found to be stable over time with a low dissolution rate of iridium but unfortunately exhibits limited OER activity, while electrochemically prepared hydrous iridium oxides, often referred to as $\mathrm{IrO}_{\mathrm{x}}$ owing to our lack of understanding of their exact chemical composition, show much improved OER activities. ${ }^{42}$ To explain such difference, recent studies suggested that partial deprotonation of hydrous $\mathrm{IrO}_{\mathrm{x}}$ catalysts leads to the decrease of the chemical potential of iridium (i.e. increased oxidation state) and the formation of so-called electrophilic ' $\mathrm{O}^{\mathrm{n}-\mathrm{s}}$ species in which electron holes are localized in $\mathrm{O} 2 p$ states. $^{43-46}$ These species are prone to react with water which serves as nucleophile following an acid-base reaction, thus reducing the barrier for $\mathrm{O}-\mathrm{O}$ bond formation and giving rise to the enhanced OER activity of hydrous $\mathrm{IrO}_{\mathrm{x}}$. However, this improved activity is at the expense of its stability since triggering the reactivity of ' $\mathrm{O}^{\mathrm{n}-\mathrm{s}}$ species with water lowers the coordination of iridium which then becomes prone to dissolution. Therefore, hydrated $\mathrm{IrO}_{\mathrm{x}}$ catalysts are found relatively unstable leading to a constant reconstruction of their surface under the OER conditions.

Encouraged by the fast development of complex transition metal oxides from the perovskite family as OER catalysts under alkaline conditions, ${ }^{9,47-50}$ complex iridium-based perovskites or pyrochlore catalysts have thus been recently studied as promising OER catalysts in acidic conditions, as summarized in Figure 2. ${ }^{51,52} \mathrm{We}$ should first recall that proper normalization of the electrocatalytic performances of OER catalysts has been a longstanding issue, as recently discussed in several review articles. ${ }^{53,54}$ This is particularly true for amorphous catalysts whose surface is poorly defined and the concentration of active sites hard to estimate. Up to date, popular methodologies to normalize the OER activity use either the specific surface area as obtained by gas adsorption following the Brunauer-Emmett-Teller (BET) theory or the electrochemically active surface area (ECSA). The most common method to study crystalline catalysts remains the BET surface area, nevertheless this normalization method possesses limitations and can hardly be transposed to accurately estimate the concentration of active sites for amorphous surfaces. ${ }^{54}$ In this paper, the OER activity of catalysts is normalized by their BET specific surface. One can observe in Figure 2a that the OER activities for $\mathrm{Ir}^{\mathrm{IV}}$-based perovskites and pyrochlores (e.g. $\mathrm{SrIrO}_{3}, \mathrm{Y}_{2} \mathrm{Ir}_{2} \mathrm{O}_{7}$ ) differ only marginally from that of Ir-M mixed oxides (e.g. $\mathrm{Li}^{-} \mathrm{IrO}_{\mathrm{x}}$ amorphous oxides, Ir-Ni oxides), despite the obvious differences in their crystallographic structures and chemical compositions (Figure 2c). This is in stark 
contrast with observations previously made for OER catalysts in alkaline media for which modifying the crystal field and the nature of the neighboring atoms could change the metaloxygen bond strength and thus affect the OER activity of transition metal oxides ${ }^{7,47,50,55}$. Furthermore, not only do the OER activities of $\operatorname{Ir}^{\text {IV }}$-based oxides appear rather insensitive to the chemical composition but the activities measured for $\operatorname{Ir}^{\mathrm{V}}$ based double perovskites are also found nearly invariant with respect to structure and chemical composition (Figure 2b). More strikingly, the OER activities measured for $\operatorname{Ir}^{\mathrm{IV}}$ - and $\operatorname{Ir}^{\mathrm{V}}$ based catalysts in acidic conditions are very similar, with an overpotential of about $0.30 \mathrm{~V} \pm 0.03$ at $1 \mathrm{~mA} / \mathrm{cm}_{\text {oxide }}{ }^{2}$ for both series. This result is in contradiction with our understanding of the OER activity for transition metal oxides, which should be greatly dependent on the iono-covalent character of the metaloxygen bond that increases with the transition metal oxidation state. Moreover, $\mathrm{Ir}^{\mathrm{V}}$-based catalysts such as $\mathrm{La}_{2} \mathrm{LiIrO}_{6}$ which seems to show promising OER activity in acidic conditions has been reported inactive in alkaline media ${ }^{44}$ while Ir $^{\text {IV }}$-based perovskites such as $\mathrm{SrIrO}_{3}$ have been found very active. ${ }^{51}$ (a)
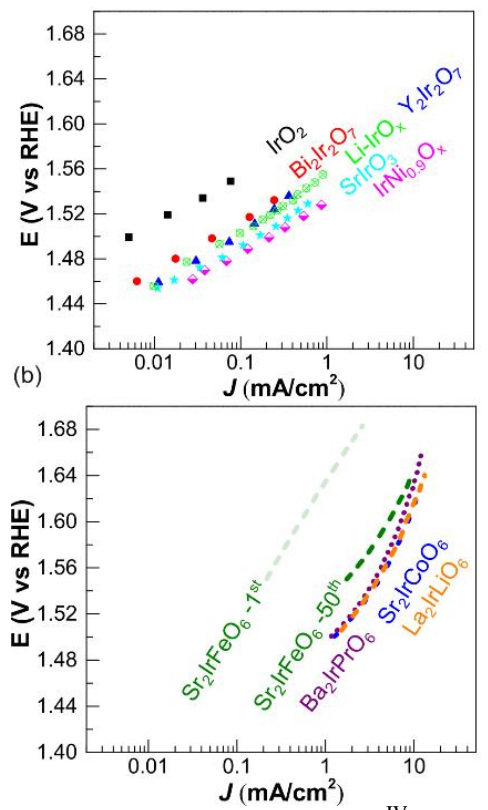

(c)

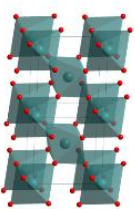

Rutile $\mathrm{IrO}_{2}$
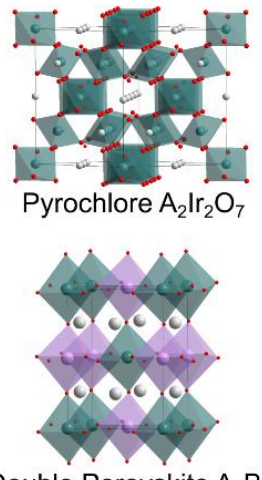

Double Perovskite $\mathrm{A}_{2} \mathrm{BlrO}_{6}$
Figure 2. Tafel plots for a) $\mathrm{Ir}^{\mathrm{IV}}$-based and b) $\mathrm{Ir}^{\mathrm{V}}$-based oxides (data for $\mathrm{IrO}_{2},{ }^{56} \mathrm{Bi}_{2} \mathrm{Ir}_{2} \mathrm{O}_{7},{ }^{52} \mathrm{Y}_{2} \mathrm{Ir}_{2} \mathrm{O}_{7}{ }^{52}{ }^{5} \mathrm{Li}_{-} \mathrm{IrO}_{\mathrm{x}},{ }^{57} \mathrm{SrIrO}_{3}{ }^{51}$ and $\mathrm{IrNi}_{0.9} \mathrm{O}_{\mathrm{x}}{ }^{58}$ were extracted from references, the OER activity for other oxides was measured following the procedure described in the Supplementary Materials). BET surface areas used to plot the data are given in Table S1 of the Supplementary Materials. c) Crystallographic structures for rutile $\mathrm{IrO}_{2}$, hexagonal $6 \mathrm{H} \mathrm{SrIrO}_{3}$, pyrochlore $\mathrm{A}_{2} \mathrm{Ir}_{2} \mathrm{O}_{7}$ and double perovskites $\mathrm{A}_{2} \mathrm{BIrO}_{6}$.

In addition to similarities in terms of OER activity, recent transmission electron microscopy (TEM) investigations revealed the formation of an amorphous $\mathrm{IrO}_{\mathrm{x}}$-type surface for numerous iridium-based OER catalysts after cycling in acidic conditions. Indeed, amorphous films were observed on the surface of $\mathrm{IrNi}^{-\mathrm{O}^{58}}$ and $6 \mathrm{H}-\mathrm{SrIrO}_{3}{ }^{51}$ catalysts after cycling (Figure 3, Figure S1 in the Supplementary Materials) while crystalline $\mathrm{IrO}_{2}$ nanoparticles were observed for $\mathrm{La}_{2} \mathrm{LiIrO}_{6}$ apart from an amorphous layer on its surface ${ }^{44}$ (Figure 3, Figure S1). As recently shown for pristine $\mathrm{SrIrO}_{3},{ }^{51}$ crystallization of $\mathrm{IrO}_{2}$ nanoparticles could arise from exposure of the surface to the electron beam, while the rate of precipitation of iridium on the surface of these catalysts might impact the crystalliza- tion process as well. Either way, the surface of these complex iridium oxides is found modified after cycling, and all these observations raised legitimate questions regarding the origin for the OER activity on the surface of Ir-based catalysts in acidic conditions.

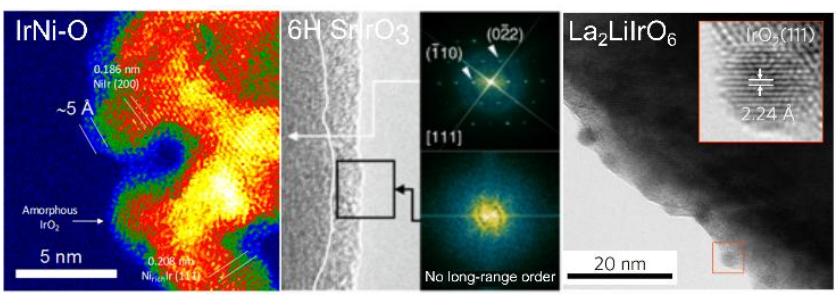

Figure 3. High resolution TEM images showing the formation of amorphous $\mathrm{IrO}_{\mathrm{x}}$ layer on the surface of $\mathrm{Ir}-\mathrm{Ni}$ mixed oxide ${ }^{58}$ (left, reprinted from ref 58 with permission) and $6-\mathrm{H} \mathrm{SrIrO}_{3}{ }^{51}$ (middle, reprinted in part from ref 51 under the terms of the Creative Commons $\quad \mathrm{CC}$ BY license: https://creativecommons.org/licenses/) while crystalline $\mathrm{IrO}_{2}$ were found on the surface of $\mathrm{La}_{2} \mathrm{LiIrO}_{6}$ after cycling ${ }^{44}$ (right, reprinted by permission from Springer Nature Customer Service Center GmbH: Springer Nature, Nature Energy, Activation of surface oxygen sites on an iridium-based model catalyst for the oxygen evolution reaction, A. Grimaud et al., 2016).

Iridium dissolution/precipitation equilibrium on the surface of OER catalysts

The surface degradation for Ir-based catalysts is triggered by the leaching of thermodynamically unstable non-noble metals as well as by the dissolution of iridium. The latter is most severe in some $\mathrm{Ir}^{\mathrm{V}}$-based double perovskites. Indeed, as shown in Figure 2c, in order to stabilize $\mathrm{Ir}^{\mathrm{V}}$-based in double perovskites, 3D structures consisting of apex-linked octahedra with alternating $\mathrm{IrO}_{6}$ and e.g. $\mathrm{BO}_{6}$ are created in $\mathrm{A}_{2} \mathrm{BIrO}_{6}$. Dissolution of these non-noble elements subsequently leads to a collective deconstruction of the apex-linked network, resulting in disconnected $\mathrm{IrO}_{6}$ fractions that are prone to dissolution in the electrolyte. Therefore, concomitant heavy dissolution of non-noble elements and iridium was observed for $\mathrm{Ir}^{\mathrm{V}}$-based double perovskites, which significantly jeopardize the catalytic stability of these $\operatorname{Ir}^{\mathrm{V}}$-based catalysts.

In order to evaluate the stability of different Ir-based catalysts, the concept of 'stability factor' (S-factor) given by the ratio of gaseous oxygen generated and the amount of dissolved iridium was recently introduced. ${ }^{42}$ In a classical corrosion scheme, the dissolution rate is assumed to follow the anodic current, which should lead to a similar S-factor for every oxide catalyst. However, the aforementioned experimental observations suggest a dissolution rate for $\mathrm{Ir}^{\mathrm{V}}$-based catalysts governed not only by the anodic current as generally assumed, but also greatly affected by factors such as associated chemical leaching of non-noble metals constituting the catalyst. The estimated stability factor for different catalysts might therefore vary and one can find a general trend with thermally prepared $\mathrm{IrO}_{2}>$ hydrated $\mathrm{IrO}_{\mathrm{x}} \approx \mathrm{Ir}^{\mathrm{IV}}$-based oxides $>\mathrm{Ir}^{\mathrm{V}}$-based oxides such as $\mathrm{Ba}_{2} \mathrm{PrIrO}_{6}, \mathrm{La}_{2} \mathrm{LiIrO}_{6}$ or $\mathrm{Sr}_{2} \mathrm{FeIrO}_{6}$ which are found the least stable.

Observing that iridium is rapidly leached out of perovskitebased catalysts even at the open-circuit voltage when no anodic current is applied, we recently demonstrated that the OER activity for these iridium oxides is in fact controlled by the redeposition of amorphous $\mathrm{IrO}_{\mathrm{x}}$ from dissolved iridium species onto the surface of the catalysts. ${ }^{59}$ Realizing this, efforts must 
be aimed at understanding this dissolution/precipitation which is evidently function of the nature of the dissolved iridium species. However, while the Pourbaix diagrams for most transition metals are well-established, the one for iridium still holds some uncertainties, especially at low $\mathrm{pH}$. In order to highlight this gap in our understanding of the nature of the iridium dissolved species, we intentionally leached out a series of double perovskites in different concentrated electrolytes $\left(\mathrm{HClO}_{4}, \mathrm{H}_{2} \mathrm{SO}_{4}\right.$, or $\left.\mathrm{HCl}\right)$ and measured their UV-Vis spectra in order to determine the strength of interaction between the dissolved Ir and the conjugated base (methods in the Supplementary Information). As shown in Figure 4 a), different soluble species are observed with the maximum absorbance shifting towards greater wavelengths following $\mathrm{HClO}_{4}<\mathrm{H}_{2} \mathrm{SO}_{4}<$ $\mathrm{HCl}$. This shift indicates that while $\mathrm{ClO}_{4}^{-}$anions might be considered as non-interacting with the dissolved iridium species, ligand exchange may occur between the iridium oxo species formed during the dissolution of the perovskite and $\mathrm{SO}_{4}{ }^{2-}$ or $\mathrm{Cl}^{-}$anions, with the exchange being stronger for $\mathrm{Cl}^{-}$ anions. Interestingly, we can qualitatively observe that $\mathrm{Sr}_{2} \mathrm{IrCoO}_{6}$ dissolves almost readily for both $\mathrm{H}_{2} \mathrm{SO}_{4}$ and $\mathrm{HCl}$ solutions but not for $\mathrm{HClO}_{4}$ (Figure 4b), pointing towards the ligand induced displacement of the dissolution equilibrium. Furthermore, precipitation of $\mathrm{SrSO}_{4}$ or other insoluble salts may affect this equilibrium as well. Consequently, $\mathrm{Sr}_{2} \mathrm{IrCoO}_{6}$ was found to exhibit stable performances in $\mathrm{HClO}_{4}$ acidic solutions (within 20 cycles) while it suffers significant degradation along cycling in $\mathrm{H}_{2} \mathrm{SO}_{4}$ (Figure 5a). One must therefore be cautious when designing new OER catalysts for acidic conditions, as well as when comparing the stability metrics for these complex OER catalysts.

(a)
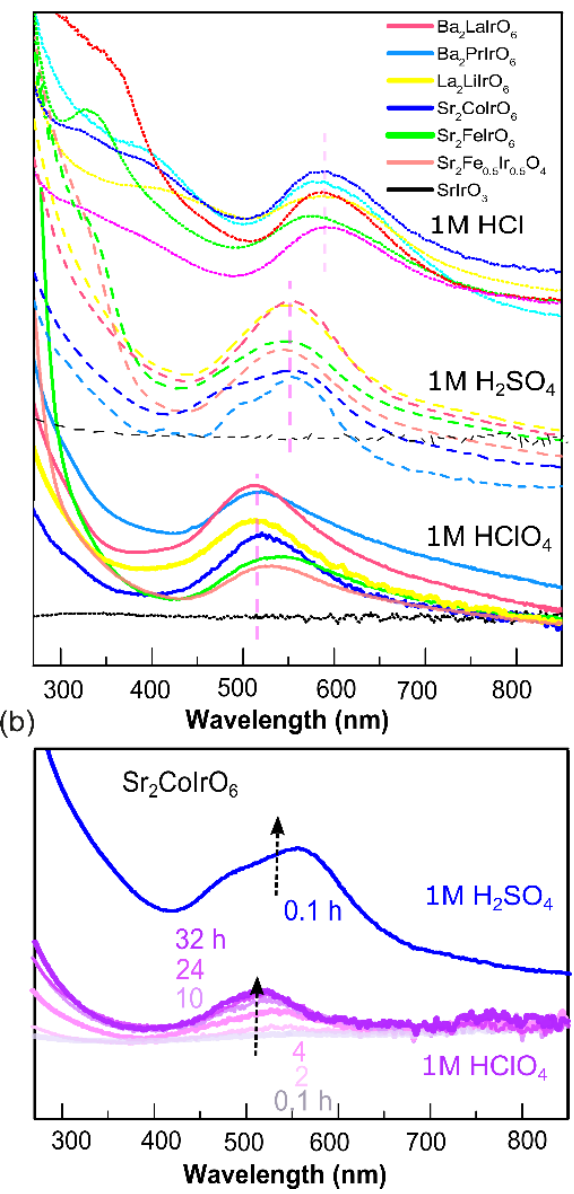

Figure 4. a) UV-Vis spectra measured for different acids in contact with $\mathrm{Ir}^{\mathrm{V}}$-based perovskite catalysts, as well as $\mathrm{Ir}^{\mathrm{IV}}$-based catalysts. b) UV-Vis spectra recorded over time for $\mathrm{Sr}_{2} \mathrm{IrCoO}_{6}$ in $1 \mathrm{M} \mathrm{H}_{2} \mathrm{SO}_{4}$ or $\mathrm{HClO}_{4}$ solutions showing the different dissolution rates in both acids.

Furthermore, the nature of anions in acidic electrolytes not only modifies the stability of the solid catalyst, but also affects the subsequent electro-deposition of $\mathrm{IrO}_{x}$ on the surface of the catalyst. To study this effect, blank glassy carbon electrodes were cycled in different acidic solutions $\left(\mathrm{H}_{2} \mathrm{SO}_{4}\right.$ or $\left.\mathrm{HClO}_{4}\right)$ containing soluble iridium species (Figure $5 \mathrm{~b}$ and Supplementary Materials). As shown in Figure $5 \mathrm{c}$ and $5 \mathrm{~d}$, the pseudocapacitive current is found to quickly increase from the $1^{\text {st }}$ to the $50^{\text {th }}$ cycle, with the appearance of both redox peaks and a capacitive envelope suggesting the deposition of $\mathrm{IrO}_{x}$ from the soluble iridium precursors in both $\mathrm{H}_{2} \mathrm{SO}_{4}$ and $\mathrm{HClO}_{4}$. However, the redox features are found different for $\mathrm{IrO}_{\mathrm{x}}$ electrodeposited in $\mathrm{H}_{2} \mathrm{SO}_{4}$ and in $\mathrm{HClO}_{4}$ (Figure 5d). Specifically, the redox potential for $\mathrm{IrO}_{\mathrm{x}}$ electrodeposited in $\mathrm{HClO}_{4}(0.89 \mathrm{~V}$ vs. RHE) are shifted to lower potential, indicating that hydrated $\mathrm{IrO}_{\mathrm{x}}$ is easier to oxidize than when electrodeposited in $\mathrm{H}_{2} \mathrm{SO}_{4}(0.96 \mathrm{~V}$ vs. RHE). This observation is in agreement with the previous work by Blakemore et al. reporting different redox behaviors and morphologies for $\mathrm{IrO}_{\mathrm{x}}$ films deposited from different organic precursors. ${ }^{60}$ Furthermore, a constant cathodic current is monitored in $\mathrm{H}_{2} \mathrm{SO}_{4}$, presumably arising from the constant cathodic electrodeposition of $\mathrm{IrO}_{\mathrm{x}}$ species that are more soluble in $\mathrm{H}_{2} \mathrm{SO}_{4}$ than in $\mathrm{HClO}_{4}$, as qualitatively discussed in Figure 4b. Nevertheless, as seen in Figure 5c, the final OER activity for the electrodeposited $\mathrm{IrO}_{\mathrm{x}}$ when scaled by the geometric surface area of the electrode is not impacted by the nature of the acidic electrolyte, despite the different redox features observed in their pseudocapacitive regions. Thus, while $\mathrm{IrO}_{\mathrm{x}}$ electro-deposited in these different conditions might have different morphologies, its impact on the intrinsic OER activities remain unclear. In our quest for designing better OER catalysts utilizing the full catalytic potential of hydrated $\mathrm{IrO}_{x}$, further investigations are needed to 1) fully understand the nature of the different iridium soluble species which define the morphology and local environment of Ir in the deposited $\mathrm{IrO}_{x}$ and 2) potentially control the density and nature of the electrodeposited $\mathrm{IrO}_{\mathrm{x}}$ active sites. Finally, the nature of the electrolyte and water structure on the stability of OER catalysts is not limited to the case of Ir-based catalysts in acidic conditions but also applies to other catalysts at different $\mathrm{pH}$. 
(a)

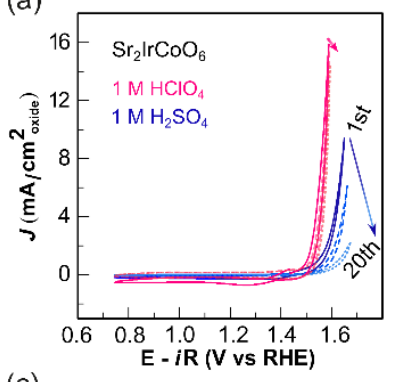

(c)

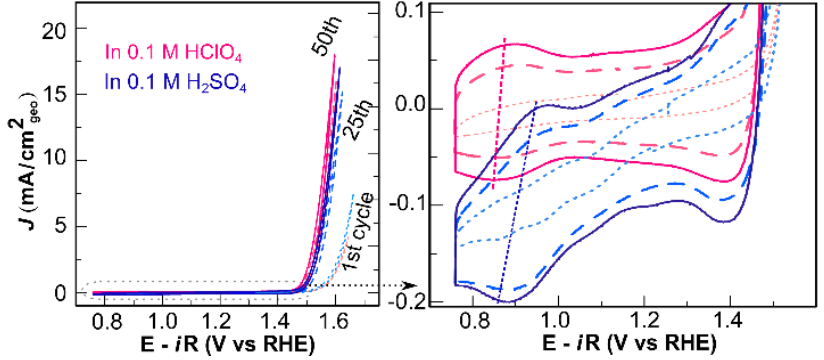

Figure 5. a) Cyclic voltammograms recorded for $\mathrm{Sr}_{2} \mathrm{IrCoO}_{6}$ in $1 \mathrm{M} \mathrm{HClO}_{4}$ and $1 \mathrm{M} \mathrm{H}_{2} \mathrm{SO}_{4}$. b) Schematic representation of the electrodeposition of dissolved iridium species. c) Cyclic voltammograms recorded for a bare glassy carbon electrode cycled in electrolytes containing dissolved iridium species in $0.1 \mathrm{M}$ $\mathrm{HClO}_{4}$ and $0.1 \mathrm{M} \mathrm{H}_{2} \mathrm{SO}_{4}$. d) The pseudo-capacitive region of $\mathbf{c}$ ).

Extending the stability window of OER catalysts in acid by the design of bulk protonated phases

Complex iridium-based perovskites, pyrochlores and mixmetal oxides appear as thermodynamically unstable in the potential-pH window of interest for OER in acidic conditions where only $\mathrm{IrO}_{2}$ and electrodeposited $\mathrm{IrO}_{\mathrm{x}}$ amorphous compounds have been reported stable above $1.23 \mathrm{~V}$ vs. RHE (Figure 6a). This observation drastically constrains our landscape for materials exploration in acid and new strategies must be developed to overcome this limitation and design new active and stable crystalline catalysts in these harsh conditions. Aside from the aforementioned strategies including confining the dissolution of iridium by using nanoporous materials or the use of substrates to stabilize the iridium-based catalysts, exploration of novel phases via topochemical synthetic strategies appear as potentially promising. For that, inspiration can be taken from the functioning of hydrous amorphous $\mathrm{IrO}_{\mathrm{x}}$ catalysts previously described. Indeed, while only adsorption/desorption events occur on the surface of thermally prepared $\mathrm{IrO}_{2}$ prior to the OER, continuous oxidation/reduction events associated with proton exchange is observed for hydrous $\mathrm{IrO}_{\mathrm{x}}$ catalysts (Figure 5b).
Recently, a series of novel bulk protonated iridium phases $\mathrm{H}_{\mathrm{x}} \mathrm{IrO}_{3}$ and $\mathrm{H}_{\mathrm{x}} \mathrm{IrO}_{4}$ was uncovered via cation exchange in acidic conditions of the lithiated parent phases $\beta-\mathrm{Li}_{2} \mathrm{IrO}_{3}$ and $\mathrm{Li}_{3} \mathrm{IrO}_{4}$, respectively. ${ }^{61,62}$ For the $\mathrm{H}_{\mathrm{x}} \mathrm{IrO}_{4}$ phase, the cation exchange reaction drives a mild structural transition from the initial O3 stacking in $\mathrm{Li}_{3} \mathrm{IrO}_{4}$ to a P3 stacking in $\mathrm{H}_{3.4} \mathrm{IrO}_{4}$, as shown in Figure 6a. In other words, the reaction is topotactic and allows the stabilization of the protonated iridate $\mathrm{H}_{3.4} \mathrm{IrO}_{4}$ with a well-defined crystal structure (Figure 6b), which is of significant difference to the amorphous hydrated $\mathrm{IrO}_{\mathrm{x}}$ with a structure parent to the rutile $\mathrm{IrO}_{2}$ phase formed on the surface of iridium metal oxides (Figure 3 ) or the amorphous hydrous $\mathrm{IrO}_{\mathrm{x}}$ formed from the oxidation of metallic $\mathrm{Ir}^{63}$. Furthermore, we could observe by operando XRD that the $\mathrm{H}_{3.4} \mathrm{IrO}_{4}$ phase remains crystalline in the potential window of 0.24 to $1.64 \mathrm{~V}$ vs. RHE in $0.1 \mathrm{M} \mathrm{HClO}_{4}$, as shown in the $2 \mathrm{D}$ contour plots in Figure 7. The concurrent OER at potential above $1.5 \mathrm{~V}$ vs. RHE does not jeopardize the crystallinity of $\mathrm{H}_{3.4} \mathrm{IrO}_{4}$. More specifically, $\mathrm{H}_{3.4} \mathrm{IrO}_{4}$ exhibits an excellent structural flexibility to reversibly release/uptake $\mathrm{H}^{+}$at this potential range, as seen by the continuous shifting of the (003) diffraction peak at $2 \theta \approx$ $19^{\circ}$, indicating continuous modification of the interlayer distance as commonly seen for layered compounds upon reversible $\mathrm{Li}^{+}$or $\mathrm{Na}^{+}$intercalation (Figure 6) ${ }^{64,65}$ Furthermore, as shown in Figure $6 \mathrm{c}, \mathrm{H}_{3.4} \mathrm{IrO}_{4}$ was observed with both stable OER currents and proton exchange redox processes for over 100 cycles. This stability might result from the charge balance phenomenon associated with the proton exchange and the concomitant change of iridium oxidation state before and during the OER. We thus believe that bulk protonated $\mathrm{H}_{\mathrm{x}} \mathrm{IrO}_{\mathrm{y}}$ phases can offer a good alternative to thermally prepared $\mathrm{IrO}_{2}$ to design OER catalysts with enhanced and stable OER activities. Furthermore, as suggested by our recent study ${ }^{61}$, the iridium dissolution in the bulk protonated phase $\mathrm{H}_{2} \mathrm{IrO}_{3}$ is largely decreased compared to other crystalline phases such as $\mathrm{SrIrO}_{3}$, providing another evidence that bulk protonated $\mathrm{H}_{\mathrm{x}} \mathrm{IrO}_{\mathrm{y}}$ phases are promising OER catalysts with stable performances. As for any new strategy, more remains to be done in order to fully uncover the real potential of such a family of protonated oxides as OER electrocatalysts. More specifically, one must determine if this stability is thermodynamic or kinetics in nature, as well as compare it with the dissolution rate previously found for amorphous hydrated $\mathrm{IrO}_{\mathrm{x}}$ catalysts which are known to be less stable than their crystalline $\mathrm{IrO}_{2}$ counterpart. ${ }^{63}$ Furthermore, topotactic cation exchange was successfully achieved starting from layered lithiated phases and a thorough exploration of this synthesis route will be needed to determine if such a strategy can be extended to other families such as tungsten bronze oxides, Ruddlesden-Popper compounds or others. 
(a)

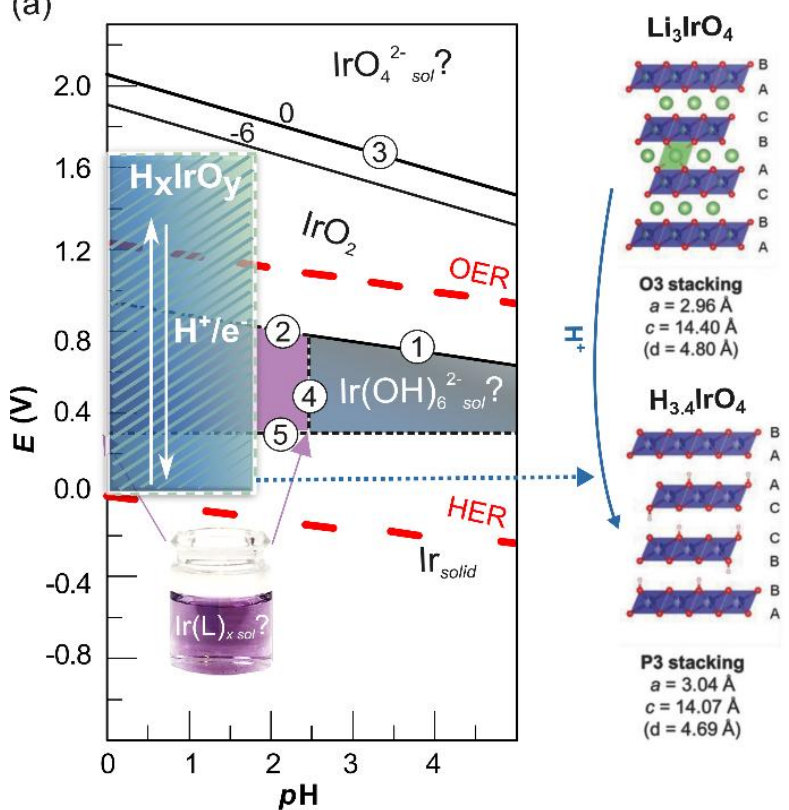

(b)

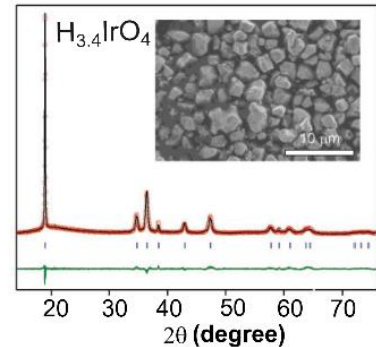

(c)

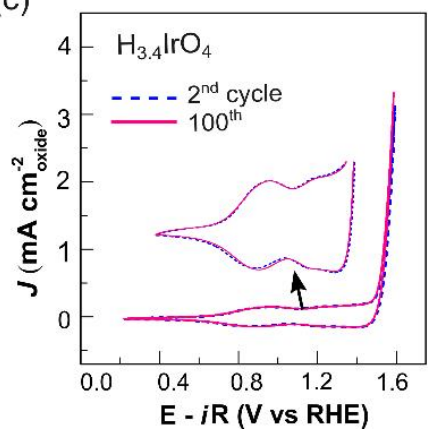

Figure 6. a) Pourbaix diagram of iridium in $\mathrm{HClO}_{4}$ solution with the shaded area indicating where stable and crystalline protonated iridates can be explored. On the right shows the structure of the protonated iridate $\mathrm{H}_{3.4} \mathrm{IrO}_{4}$ that was obtained via a proton exchange reaction from $\mathrm{Li}_{3} \mathrm{IrO}_{4}$ in acid ${ }^{62} \mathbf{b}$ ) Rietveld refinement of the XRD pattern of $\mathrm{H}_{3.4} \mathrm{IrO}_{4}$ with in red the experimental points, in black the simulated pattern, in green the difference between observed and simulated and the blue ticks are the Bragg reflections. An SEM micrograph of the pristine $\mathrm{H}_{3.4} \mathrm{IrO}_{4}$ is shown in the inset ${ }^{62}$. c) The CVs recorded for $\mathrm{H}_{3.4} \mathrm{IrO}_{4}$ in $0.1 \mathrm{M} \mathrm{HClO}_{4}$ for 100 cycles at a scan rate of $10 \mathrm{mV} / \mathrm{s}$. The current is normalized by the BET surface area $\left(2.23 \mathrm{~m}^{2} / \mathrm{g}\right)$. The inset displays the enlarged capacitive region showing the redox processes associated with $\mathrm{H}^{+} / \mathrm{e}^{-}$exchange in $\mathrm{H}_{3.4} \mathrm{IrO}_{4}$. Figure a) and b) adapted with permission from Proton Ion Exchange Reaction in $\mathrm{Li}_{3} \mathrm{IrO}_{4}$ : $\mathrm{A}$ Way to $\mathrm{New}_{3+\mathrm{x}} \mathrm{IrO}_{4}$ Phases Electrochemically Active in Both Aqueous and Nonaqueous Electrolytes, A. J. Perez et al., Advanced Energy Materials, 2019,

Reversible $\mathrm{H}^{+} / \mathrm{e}^{-}$exchange in $\mathrm{H}_{3.4} \mathrm{IrO}_{4}$
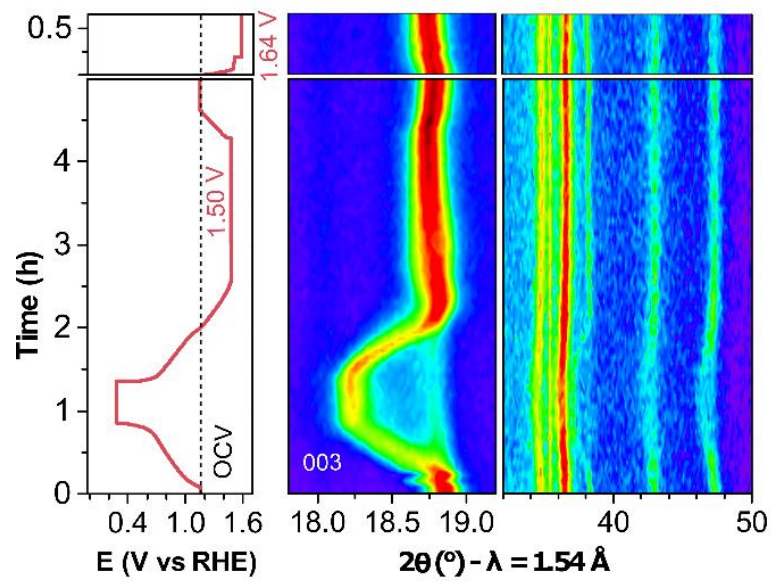

Figure 7. Operando XRD study of $\mathrm{H}_{3.4} \mathrm{IrO}_{4}$ in $0.1 \mathrm{M} \mathrm{HClO}_{4}$ suggesting its structural flexibility to reversibly release/uptake $\mathrm{H}^{+}$in the potential range of 0.24 to $1.64 \mathrm{~V}$ vs. RHE. On the left is shown the electrochemical cycling carried out during continuous XRD measurement. A 2D contour plot of the evolution of resulting patterns aligned with the electrochemistry is shown on the right. Only relevant $2 \theta$ ranges are displayed here.

\section{Controlling the water structure in the environment of} active sites

From the example of iridium oxides used as OER catalysts in acidic conditions, it appears that the next frontier to conquer regarding the development of water splitting catalysts is the control over the complex equilibrium/ion exchanges occurring
John

Wiley

and

Sons.

at the interface between the oxide catalysts and the electrolyte. Nevertheless, in order to achieve such fine control, one critical piece of information is cruelly missing: the understanding of the water structure in the environment of the active sites. Even if recent results are slowly uncovering this effect (see the discussion below), our understanding related to water solvation structure on the OER activity of transition metal oxides is certainly less advanced than our comprehension regarding the hydrogen evolution reaction (HER).

Indeed, poised by the observations that Pt performed better in strongly acidic conditions than in either neutral or alkaline conditions, ${ }^{23,66-68}$ researchers have slowly uncovered the effect of $\mathrm{pH}$ and of the water solvation structure on the HER performances of Pt. In acidic media, the proton discharge (Volmer step: $\mathrm{H}^{+}+\mathrm{e}^{-} \rightleftharpoons \mathrm{H}_{\mathrm{ad}}$ ) on the electrode is known to be fast and the reaction rate is controlled by the $\mathrm{H}_{2(\mathrm{~g})}$ evolution. ${ }^{69,70}$ On the contrary, $\mathrm{H}_{2} \mathrm{O}$ dissociation-adsorption was proposed to be the rate-determining step in alkaline media due to the very low concentration of protons, resulting in large penalties for the HER kinetics. ${ }^{67,71}$ This slower kinetics for reducing $\mathrm{H}_{2} \mathrm{O}$ when compared to $\mathrm{H}^{+}$could arise from both the difficulty to break the $\mathrm{O}-\mathrm{H}$ bond from water ${ }^{67}$ and the difficulty to evacuate $\mathrm{OH}^{-}$ ions generated during water reduction, ${ }^{23}$ thus modifying the reaction pathway. Either way, adding some oxophilic $\mathrm{Ni}(\mathrm{OH})_{2}$ islands to the surface of $\mathrm{Pt}(111)$ has proved to enhance the HER kinetics for Pt in alkaline conditions. ${ }^{67}$ This effect is even more pronounced when alkali cations such as $\mathrm{Li}^{+}$are added to the electrolyte, thanks to their interaction with water/hydroxyl ions and $\mathrm{Ni}(\mathrm{OH})_{2}$ on the surface of the catalyst. ${ }^{67}$ Furthermore, comparing the $\mathrm{pH}$ dependence observed for the HER activity of Pt with the one measured for the underpotential deposition of hydrogen $\left(\mathrm{H}_{\mathrm{UPD}}\right)$ that precedes the HER during cathodic 
scan, discrepancies could be observed. Indeed, while the HER kinetics for $\mathrm{Pt}(111)$ shows $\mathrm{pH}$ dependence, the $\mathrm{H}_{\mathrm{UPD}}$ energy does not show any. This indicates that the HER rate is not solely controlled by the energetics of proton adsorption ${ }^{23,67}$ and is rather governed by the modification of the double-layer structure. Indeed, as the potential of zero free charge (pzfc) is quasi-invariant with $\mathrm{pH}$ while the one for the HER is more negative (Nernst equation), the electrical field and so water rigidity at the $\mathrm{Pt}$ interface increases with the $\mathrm{pH}$, which slows down water-ions transfer (proton adsorption / hydroxide desorption) across the double layer and hence the HER rate. ${ }^{23}$ Overall, the energetics for proton transfer from the bulk of the electrolyte to the catalyst's surface can be schematically expressed as: $:^{72}$

$$
\Delta G^{*}=W_{H^{+}}+\Delta G_{\text {desolv }}+\Phi^{*}
$$

with $W_{H^{+}}$the work to transfer a solvated proton from the outer to the inner Helmotz plane, $\Delta G_{\text {desolv }}$ the free energy to partially desolvate a proton which is also the energy to deform the solvation sphere in the electrical field and $\Phi^{*}$ the energy to transfer an electron from the Fermi level of the catalyst to the inner Helmotz plane of the double layer at the catalyst/solvent interface, each term being interdependent to the others. ${ }^{72}$ Explained in a very intuitive manner, the proton must thus convert entropy into enthalpy when moving from the bulk of the electrolyte to the interface, the entropy being greater at lower $\mathrm{pH}$ due to the stronger electric field. ${ }^{73}$

For the OER, proper comparisons of the electrocatalytic activity in alkaline and in acidic conditions is mainly hindered by the limited stability of most transition metal oxides under both conditions, as discussed above. Consequently, only thermally prepared $\mathrm{IrO}_{2}$ is stable enough to compare the OER kinetics in both alkaline and acidic media. While an initial report using $\mathrm{IrO}_{2}$ nanoparticles pointed towards a higher activity in acidic conditions ${ }^{41}$, a recent study on an $\mathrm{IrO}_{2}$ thin-film focusing on the interplay between the $\mathrm{OH}_{\mathrm{ad}}$ and $\mathrm{O}_{\mathrm{ad}}$ adsorption energies and the OER kinetics in different electrolytes pointed towards faster kinetics for $\mathrm{IrO}_{2}$ in alkaline solution than in acidic media ${ }^{26}$. In this study, two parallel pathways were proposed for the formation of $\mathrm{OOH}_{\mathrm{ad}}$ (acidic: $\mathrm{O}_{\mathrm{ad}}+\mathrm{H}_{2} \mathrm{O} \rightarrow \mathrm{OOH}_{\mathrm{ad}}$ $+\mathrm{H}^{+}+\mathrm{e}^{-}$; alkaline: $\left.\mathrm{O}_{\mathrm{ad}}+\mathrm{OH}^{-} \rightarrow \mathrm{OOH}_{\mathrm{ad}}+\mathrm{H}^{+}+\mathrm{e}^{-}\right)$and the alkaline pathway was assumed to have greater kinetics than the acidic one. In acidic media, the proton-independent acidic pathway is dominant and thus the OER activity follows the formation energy of $\mathrm{OOH}_{\text {ad }}$ intermediate which is observed to increase with increasing $\mathrm{pH}$. In strong alkaline media, the alkaline pathway becomes dominant due to the availability of $\mathrm{OH}^{-}$. As a result, the OER kinetic becomes faster in stronger base, despite the observed increased formation energy of the $\mathrm{OOH}_{\mathrm{ad}}$, which is in good agreement with previous observations made for transition metal oxides. ${ }^{74-76}$ Nevertheless, the dependence in the concentration of $\mathrm{OH}^{-}$was proposed to cause the activity of $\mathrm{IrO}_{2}$ not to scale linearly with $\Delta G_{\mathrm{OOH}}$ and therefore to disobey the volcano relationship. ${ }^{26}$ Given that only the electrolyte composition is modified while keeping the surface of the catalyst unaffected, the authors concluded that other factors must be taken into account to explain such observation. Hence, the solvation structure in the vicinity of the active sites as well as specific interactions with cations on the surface of the OER catalysts ${ }^{77}$ can affect the energetics and the structure of the intermediates and thus break the scaling relationship for the OER intermediates in alkaline conditions.
A similar observation was made for the oxygen reduction reaction (ORR) on different Pt-alloys for which the activation enthalpy remains constant while the ORR activity is drastically improved when compared to pure $\mathrm{Pt}^{78}$ The improvement for the ORR activity on Pt-alloys is proposed to originate from the pre-exponential factor of the rate law which is given by the entropies of activation as well as the number of active sites. ${ }^{79}$ Indeed, following the rate law from the transition-state theory, the rate of a given reaction would be controlled by the free activation energy $\Delta G^{*}$ according to:

$$
r \propto A \exp \left(\frac{-\Delta G^{*}}{R T}\right)
$$

with A being the pre-exponential factor. Additionally, the rate of the reaction can be expressed using a derived Arrhenius law in which an entropic term is introduced into the preexponential term:

$$
\begin{gathered}
r \propto A^{\prime} \exp \left(\frac{-E_{a}}{R T}\right) \\
\text { with } A^{\prime} \propto \exp \left(\frac{-\Delta S^{*}}{R}\right)
\end{gathered}
$$

with $E_{a}$ the apparent activation energy and $\Delta S^{*}$ the entropy of activation from the transition-state theory. ${ }^{80}$ If following a socalled Bronsted-Evans-Polanyi relation, ${ }^{81,82}$ the activation energy $\mathrm{E}_{\mathrm{a}}$ linked to the binding energy of oxygen $\left(\Delta G_{0}\right)$ should define the OER kinetics. When extrapolating the results from previous work by Bockris and Otagawa, ${ }^{83}$ the apparent activation energy for the OER is found to decrease linearly with increasing current density, from $110 \mathrm{~kJ} / \mathrm{mol}$ for $\mathrm{La}_{0.8} \mathrm{Sr}_{0.2} \mathrm{CrO}_{3}$ and $98 \mathrm{~kJ} / \mathrm{mol}$ for $\mathrm{LaMnO}_{3}$ to 75 and $71 \mathrm{~kJ} / \mathrm{mol}$ for $\mathrm{La}_{0.6} \mathrm{Sr}_{0.4} \mathrm{CoO}_{3}$ and $\mathrm{LaNiO}_{3}$ at $300 \mathrm{mV}$, respectively (Figure $8 \mathrm{a}$ ). Therefore, when comparing a large variety of transition metal oxides, the apparent activation energy and therefore the binding energy of the rate-determining intermediate remains a powerful descriptor for the OER activity. Nevertheless, recent studies have highlighted that, for the most active transition metal oxides, the OER kinetics are greatly influenced by the concentration of $\mathrm{OH}^{-}$for $\mathrm{LaNiO}_{3}{ }^{84}$ and $\mathrm{La}_{1-\mathrm{x}} \mathrm{Sr}_{\mathrm{x}} \mathrm{CoO}_{3}{ }^{75}$, as shown in Figure 8 b). Interestingly, the activation energy measured for these compounds is very close to the one reported for water autoprotolysis. ${ }^{85-87}$ Both observations raise questions about the interactions that govern the OER kinetics. Similar to what was found for the HER in alkaline conditions, weak interactions such as hydrogen bonding or ion-water interactions that modify the $\mathrm{O}-\mathrm{H}$ bond dissociation and/or the adsorption of $\mathrm{OH}^{-}$on the surface of the OER catalysts could be involved.

Recent studies were therefore carried out to investigate the effect of modifying the water composition and/or solvation properties on the OER kinetics. ${ }^{85-87}$ Indeed, the strong interactions between adsorbates on the surface of $\mathrm{IrO}_{2}$ such as $* \mathrm{OH}$ and $* \mathrm{O}$ and cations in solution depending on their Lewis acidity, with for instance $\mathrm{Li}^{+}$stabilizing the $* \mathrm{OH}$ intermediate more than $\mathrm{K}^{+26,88}$ and thus modifying the OER activity, ${ }^{26}$ as recently been suggested. In contrast to this observation based on $\mathrm{IrO}_{2}$, large alkali cations $\left(\mathrm{Cs}^{+}>\mathrm{K}^{+} \sim \mathrm{Na}^{+}>\mathrm{Li}^{+}\right)$were found to dramatically enhance the OER activity of Fe-containing $\mathrm{NiOOH} .{ }^{89,90}$ Interestingly, only a very weak cation effect was observed $\left(\mathrm{Cs}^{+} \sim \mathrm{K}^{+} \sim \mathrm{Na}^{+}\right)$for "Fe-free" $\mathrm{NiOOH}$ which shows limited OER activity when compared to their Fe-containing counterparts, with the only exception of $\mathrm{Li}^{+}$which is found to reduce the OER activity. The question then arises regarding the modification of the intermediates which results from the 
competition between the following effects: modification of water hydrogen bonding network in the vicinity of the active site, specific cation/anion interactions with the catalysts surface and finally cation intercalation in the porosity and/or the structure of the catalyst. Furthermore, moving the alkali cations, the use of large hydrophobic organic cations such as tetramethylammonium cations $\left(\mathrm{TMA}^{+}\right)$was found to greatly reduce the OER activity for $\mathrm{Fe}$-containing NiOOH. ${ }^{89}$ Similarly, we observed that the presence of $\mathrm{TMA}^{+}$also reduces the OER activity of $\mathrm{La}_{0.5} \mathrm{Sr}_{0.5} \mathrm{CoO}_{3-\delta}$ while that of the less active $\mathrm{LaCoO}_{3}$ (compared to $\mathrm{La}_{0.5} \mathrm{Sr}_{0.5} \mathrm{CoO}_{3-\delta}$ ) remains unaffected. ${ }^{91}$ Altogether, these observations indicate that cation or $\mathrm{pH}$ effects on the OER kinetics predominantly appear for the most active catalysts for which the rate of oxygen evolution may not be governed by the energy of the intermediates, as discussed above. Rather, these effects can originate from the hydration enthalpy of cations that controls the proton acidity in water ${ }^{92}$ or from the water structure at the electrochemical interface which is dependent on the nature of the cations, or both. Furthermore, special care must be exercised when studying complex oxides such as perovskites, since A-site cations such as lanthanides leached under OER conditions can also interact with the surface of these catalysts that often reconstruct in the form of an oxyhydroxide film. ${ }^{93-95}$

(a)

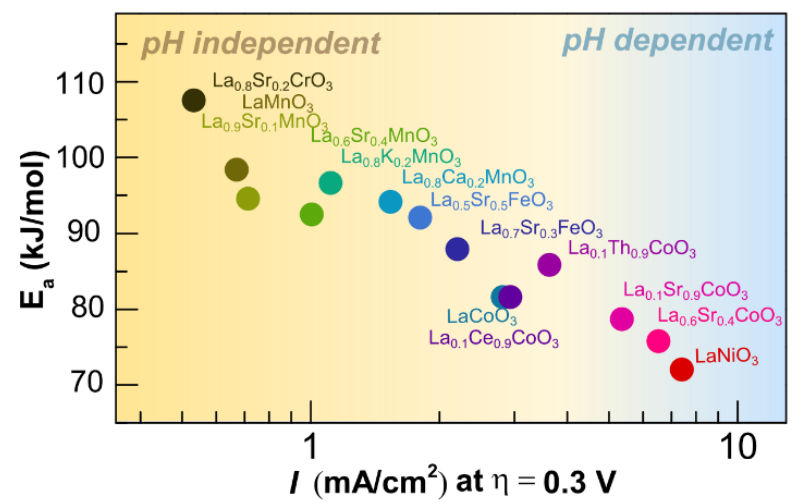

(b)
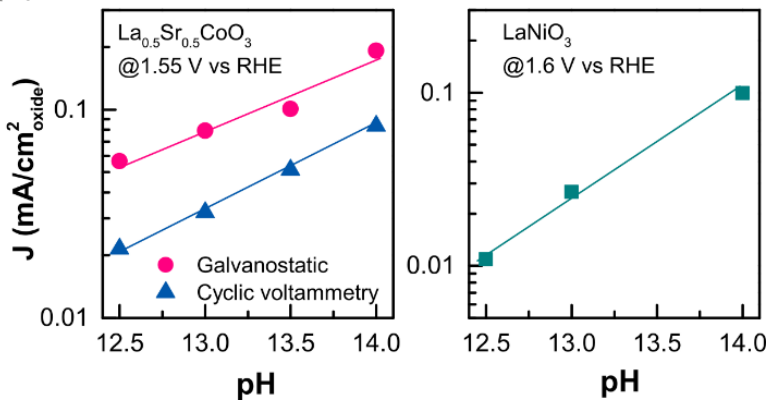

Figure 8. a) Apparent activation energies as reported by Otagawa and Bockris for perovskites OER catalysts as a function of the OER current density measured at $300 \mathrm{mV}$ overpotential. ${ }^{83}$ b) OER current density as a function of $\mathrm{pH}$ for $\mathrm{La}_{0.5} \mathrm{Sr}_{0.5} \mathrm{CoO}_{3-\delta}$ (left) and $\mathrm{LaNiO}_{3}$ (right). ${ }^{75,84}$

To gain insight into the origin of these ion/pH dependent effects, the concept of the chaotropicity or kosmotropicity of an ion can be introduced. As widely discussed in the field of liquid-liquid extraction, ${ }^{96-99}$ ions (cations and anions) in solution can be divided into two categories depending on their ability to structure (kosmotropic) or disorder (chaotropic) the water hydrogen bond network. Experimentally, the chaotropicity or kosmotropicity of ions is determined by measuring the evolution of the viscosity of the solution containing the ions of interest as a function of their concentration. Doing so, the so-called Jones-Dole equation:

$$
\frac{\eta}{\eta^{\circ}}-1=A c^{\frac{1}{2}}+B c+\cdots
$$

with $\eta$ the viscosity of the solution and $c$ the concentration of ions in solution is empirically used to sort out chaotrope and kosmotrope ions based on the $\mathrm{B}$ coefficient $(\mathrm{B}>0$ for kosmotrope and B $<0$ for chaotrope ions). As shown in Figure 9, the B coefficient measured for different cations such as alkaline cations $\left(\mathrm{Li}^{+}, \mathrm{Na}^{+}\right.$or $\left.\mathrm{K}^{+}\right)$, organic cations $\left(\mathrm{TMA}^{+}\right.$and other tetraalkylammonium cations) as well as $\mathrm{H}_{3} \mathrm{O}^{+}$does not follow the enthalpy of hydration for these cations. Such deviation reveals the entropic nature for the water hydrogen bond network ordering or disordering effect of cations in solution, ${ }^{77}$ with $\mathrm{Li}^{+}$and $\mathrm{TMA}^{+}$having a structuring effect on the water hydrogen bond network while $\mathrm{K}^{+}$has a very weak destructuring effect. Hence, when revisiting the difference in OER kinetics measured for amorphous $\mathrm{NiFe}(\mathrm{OH})_{2}$ films or for crystalline $\mathrm{La}_{0.5} \mathrm{Sr}_{0.5} \mathrm{CoO}_{3-\delta}$ in $\mathrm{KOH}$ and $\mathrm{TMAOH}$, one can conclude that the main effect is most probably not related to the difference of hydration enthalpies between both cations ($203 \mathrm{~kJ} / \mathrm{mol}$ for $\mathrm{TMA}^{+}$compared to $-320 \mathrm{~kJ} / \mathrm{mol}$ for $\mathrm{K}^{+}$). Instead, it presumably arises from the modification of the water hydrogen bond network in the electric double layer when changing from $\mathrm{K}^{+}$to $\mathrm{TMA}^{+}$. Furthermore, as previously discussed, the presence of cations can also affect the OER activity by self-insertion into the porous structure of $\mathrm{NiOOH}$ in addition to hydration enthalpy which modifies the energetics of the intermediates and the water structuring effect. ${ }^{90}$ Future work is thus needed to fully understand and dissociate all these different effects.

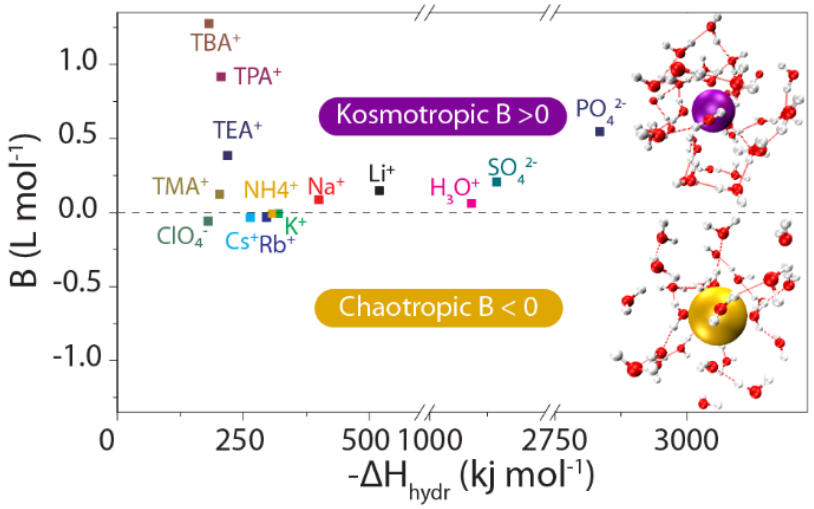

Figure 9. B coefficients from the Jones-Dole equation as obtained by viscosity measurements for different cations and anions plotted against their hydration enthalpy. The inset displays an illustration for the water structure as found around kosmotropic and chaotropic ions.

In light of the effect of ions observed on the performances of the most active OER catalysts, one must therefore consider more than just the binding energy of oxygen intermediates on the surface of the catalyst. Indeed, effects related to the free energy to deform the solvation structure in the electric field, the free energy to transfer hydroxyl ions from the outer to the inner Helmotz plane (in alkaline conditions) as well as the work to transfer protons from the inner to the outer Helmotz plane (in acidic conditions) must be taken into consideration. ${ }^{23}$ 
As discussed for the HER, the stronger the electric field at the interface, the more rigid the water structure. ${ }^{23}$ Specific adsorption occurring before any charge transfer with the electrolyte, such as the $\mathrm{H}_{\mathrm{UPD}}$, hence quenches the electrical field and renders the water structure less rigid. Nevertheless, the nature of the double layer for OER catalysts is largely unknown and it remains uncertain if such adsorption processes occur prior to the OER on the surface of transition metal oxides. Our understanding on how the structure of the bulk electrolyte translates to the structure of water in the vicinity of the active sites is thus elusive. In order to push our understanding further on how the bulk solvation structure extends to the electrochemical interface, control experiments must therefore be performed. This will only be possible through the use of thin-film electrodes deprived of binder and carbon additives and with well-defined surface areas and active sites. Furthermore, while the control of such weak interactions was so far only achieved by tuning the composition of the electrolyte, and therefore the solvation structure of water, coating strategies could be envisioned to selectively modify the pzfc of transition metal oxides as well as their proton affinity. ${ }^{91}$ Moreover, the water structure affects not only the OER activity but may also modify the stability of the catalysts, as illustrated in Figure 5a. Further work will therefore be needed to explore in depth the effect of electrolyte composition in alkaline conditions on the stability of OER catalysts. One can thus foresee the design of OER catalysts to integrate, in addition to bulk properties that have been widely explored in the past few years, even more design principles originating from sol-gel or colloids chemistry. Nevertheless, how these effects will translate into a real water electrolyzer in which a membrane is used remains to be seen as the transport properties of ions will be drastically modified.

\section{Conclusion}

Through different examples, we have highlighted recent developments in the field of water splitting catalyst design. Driven by the finding of physical descriptors for the OER activity of transition metal oxides, numerous catalysts were proposed in the past decade and our knowledge about catalysts' operation has certainly advanced when compared to pioneering works made on perovskites or binary oxides. Nevertheless, the field is now facing a major difficulty, which is to design not only very active catalysts, but also solids that show sufficient stability under these very oxidizing conditions. For that, as emphasized by the recent development of iridium-based OER catalysts for acidic conditions, a thorough understanding of the dissolution/precipitation equilibrium is necessary. This understanding relies first on assessing the intermediates responsible for the dissolution of transition metal oxides, then on uncovering the exact nature of the dissolved species and their interactions with the electrolyte which, in turn, controls the electrochemical redeposition of active species on the surface of the catalyst. While most catalysts are not stable under these acidic conditions, we believe that the development of bulk protonated oxides can unlock the design of active and stable electrocatalysts for acidic conditions, owing to the reversible bulk exchange of protons that allows the counter-balancing of charge associated with the iridium oxidation and the chemical reaction with water. ${ }^{61}$ Finally, we believe that the next step in achieving enhanced electrocatalytic properties in solids lies within the structure of water in the vicinity of the active sites. We therefore highlight the importance of entropic terms relat- ed to the ability of ions to structure or destructure the water hydrogen bond that can be tuned to selectively control the OER activity of the most active transition metal oxides.

\section{ASSOCIATED CONTENT}

Supporting Information. Detailed experimental procedures for electrochemical measurements, UV-vis, Operando X-ray diffraction, and BET measurements. Data extracted for Figure 2 and 8. This material is available free of charge via the Internet at http://pubs.acs.org.

\section{AUTHOR INFORMATION}

\section{Corresponding Author}

*Alexis Grimaud

alexis.grimaud@college-de-france.fr

ORCID

Ronghuan Zhang: 0000-0003-1855-619X

Paul E. Pearce: 0000-0001-5178-2637

Yan Duan: 0000-0001-7682-1575

Nicolas Dubouis: 0000-0001-8698-7202

Thomas Marchandier: 0000-0001-9643-1064

Alexis Grimaud: 0000-0002-9966-205X

\section{Author Contributions}

The manuscript was written through contributions of all authors.

\section{ACKNOWLEDGMENT}

A.G. and R.Z. acknowledge financial support from the ANR MIDWAY (Project ID: ANR-17-CE05-0008). A.G. would like to that the ANR for financial support under the project LABEX STORE-EX.

\section{REFERENCES}

(1) Markovic, N. M. Electrocatalysis: Interfacing Electrochemistry. Nat. Mater. 2013, 12 (2), 101-102.

(2) Tarascon, J.-M.; Armand, M. Issues and Challenges Facing Rechargeable Lithium Batteries. Nature 2001, 414 (6861), 359367.

(3) Armand, M.; Tarascon, J.-M. Building Better Batteries. Nature 2008, 451, 652

(4) Padhi, A. K.; Nanjundaswamy, K. S.; Goodenough, J. B. Phospho- olivines as Positive- Electrode Materials for Rechargeable Lithium Batteries. J. Electrochem. Soc. 1997, 144 (4), 1188-1194.

(5) Han, J.-T.; Huang, Y.-H.; Goodenough, J. B. New Anode Framework for Rechargeable Lithium Batteries. Chem. Mater. 2011, 23 (8), 2027-2029.

(6) Park, K.; Yu, B.-C.; Jung, J.-W.; Li, Y.; Zhou, W.; Gao, H.; Son, S.; Goodenough, J. B. Electrochemical Nature of the Cathode Interface for a Solid-State Lithium-Ion Battery: Interface between $\mathrm{LiCoO}_{2}$ and Garnet- $\mathrm{Li}_{7} \mathrm{La}_{3} \mathrm{Zr}_{2} \mathrm{O}_{12}$. Chem. Mater. 2016, 28 (21), 8051-8059.

(7) Wei, C.; Feng, Z.; Scherer, G. G.; Barber, J.; Shao- Horn, Y.; $\mathrm{Xu}, \mathrm{Z}$. J. Cations in Octahedral Sites: A Descriptor for Oxygen Electrocatalysis on Transition- Metal Spinels. Adv. Mater. 2017, 29 (23), 1606800

(8) Hong, W. T.; Welsch, R. E.; Shao-Horn, Y. Descriptors of Oxygen-Evolution Activity for Oxides: A Statistical Evaluation. J. Phys. Chem. C 2016, 120 (1), 78-86.

(9) Suntivich, J.; May, K. J.; Gasteiger, H. A.; Goodenough, J. B.; Shao-Horn, Y. A Perovskite Oxide Optimized for Oxygen Evolution Catalysis from Molecular Orbital Principles. Science (80-. ). 2011, 334 (6061), 1383-1385. 
Trasatti, S. Work Function, Electronegativity, and Electrochemical Behaviour of Metals. J. Electroanal. Chem. Interfacial Electrochem. 1972, 39 (1), 163-184.

Nørskov, J. K.; Bligaard, T.; Logadottir, A.; Kitchin, J. R.; Chen, J. G.; Pandelov, S.; Stimming, U. Trends in the Exchange Current for Hydrogen Evolution. J. Electrochem. Soc. 2005, 152 (3), J23.

(12) Sheng, W.; Myint, M.; Chen, J. G.; Yan, Y. Correlating the Hydrogen Evolution Reaction Activity in Alkaline Electrolytes with the Hydrogen Binding Energy on Monometallic Surfaces. Energy Environ. Sci. 2013, 6 (5), 1509-1512.

(13) Evans, M. G.; Polanyi, M. Further Considerations on the Thermodynamics of Chemical Equilibria and Reaction Rates. Trans. Faraday Soc. 1936, 32 (0), 1333-1360.

(14) Man, I. C.; Su, H.; Calle- Vallejo, F.; Hansen, H. A.; Martínez, J. I.; Inoglu, N. G.; Kitchin, J.; Jaramillo, T. F.; Nørskov, J. K.; Rossmeisl, J. Universality in Oxygen Evolution Electrocatalysis on Oxide Surfaces. ChemCatChem 2011, 3 (7), 1159-1165.

(15) Beer, H. B. The Invention and Industrial Development of Metal Anodes. J. Electrochem. Soc. 1980, 127 (8), 303C-307C.

(16) Trasatti, S. Electrocatalysis by Oxides-attempt at a Unifying Approach. J. Electroanal. Chem. Interfacial Electrochem. 1980, 111 (1), 125-131.

(17) Chang, S. H.; Danilovic, N.; Chang, K.-C.; Subbaraman, R.; Paulikas, A. P.; Fong, D. D.; Highland, M. J.; Baldo, P. M.; Stamenkovic, V. R.; Freeland, J. W. Functional Links between Stability and Reactivity of Strontium Ruthenate Single Crystals during Oxygen Evolution. Nat. Commun. 2014, 5, 4191.

(18) Risch, M.; Grimaud, A.; May, K. J.; Stoerzinger, K. A.; Chen, T. J.; Mansour, A. N.; Shao-Horn, Y. Structural Changes of Cobalt-Based Perovskites upon Water Oxidation Investigated by EXAFS. J. Phys. Chem. C 2013, 117 (17), 8628-8635.

(19) Rossmeisl, J.; Logadottir, A.; Nørskov, J. K. Electrolysis of Water on (Oxidized) Metal Surfaces. Chem. Phys. 2005, 319 (1), 178-184

(20) Hong, W.; Stoerzinger, K. A.; Lee, Y.-L.; Giordano, L.; Grimaud, A. J. L.; Johnson, A. M.; Hwang, J.; Crumlin, E.; Yang, W.; Shao-Horn, Y. Charge-Transfer-Energy-Dependent Oxygen Evolution Reaction Mechanisms for Perovskite Oxides. Energy Environ. Sci. 2017, 10 (10), 2190-2200.

(21) Jaramillo, T. F.; Jørgensen, K. P.; Bonde, J.; Nielsen, J. H.; Horch, S.; Chorkendorff, I. Identification of Active Edge Sites for Electrochemical $\mathrm{H}_{2}$ Evolution from $\mathrm{MoS}_{2}$ Nanocatalysts. Science (80-. ). 2007, 317 (5834), 100-102.

(22) Chen, X.; McCrum, I. T.; Schwarz, K. A.; Janik, M. J.; Koper, M. T. M. Co-Adsorption of Cations as the Cause of the Apparent PH Dependence of Hydrogen Adsorption on a Stepped Platinum Single-Crystal Electrode. Angew. Chemie 2017, 129 (47), 15221-15225.

(23) Ledezma-Yanez, I.; Wallace, W. D. Z.; Sebastián-Pascual, P.; Climent, V.; Feliu, J. M.; Koper, M. T. M. Interfacial Water Reorganization as a PH-Dependent Descriptor of the Hydrogen Evolution Rate on Platinum Electrodes. Nat. Energy 2017, 2 (4), 17031.

(24) Chang, S. H.; Connell, J. G.; Danilovic, N.; Subbaraman, R.; Chang, K.-C.; Stamenkovic, V. R.; Markovic, N. M. Activitystability Relationship in the Surface Electrochemistry of the Oxygen Evolution Reaction. Faraday Discuss. 2015, 176, 125133.

(25) May, K. J.; Carlton, C. E.; Stoerzinger, K. a.; Risch, M.; Suntivich, J.; Lee, Y. L.; Grimaud, A.; Shao-Horn, Y. Influence of Oxygen Evolution during Water Oxidation on the Surface of Perovskite Oxide Catalysts. J. Phys. Chem. Lett. 2012, 3 (22), 3264-3270.

(26) Kuo, D.-Y.; Paik, H.; Kloppenburg, J.; Faeth, B.; Shen, K. M.; Schlom, D. G.; Hautier, G.; Suntivich, J. Measurements of Oxygen Electroadsorption Energies and Oxygen Evolution Reaction on $\mathrm{RuO}_{2}$ (110): A Discussion of the Sabatier Principle and Its Role in Electrocatalysis. J. Am. Chem. Soc. 2018, 140 (50), 17597-17605.

(27) Kim, Y.-T.; Lopes, P. P.; Park, S.-A.; Lee, A.-Y.; Lim, J.; Lee, H.; Back, S.; Jung, Y.; Danilovic, N.; Stamenkovic, V.; et al. Balancing Activity, Stability and Conductivity of Nanoporous Core-Shell Iridium/Iridium Oxide Oxygen Evolution Catalysts. Nat. Commun. 2017, 8 (1), 1449.
El-Moneim, A. A.; Kumagai, N.; Asami, K.; Hashimoto, K. Nanocrystalline Manganese-Molybdenum-Tungsten Oxide Anodes for Oxygen Evolution in Acidic Seawater Electrolysis. Mater. Trans. 2005, 46 (2), 309-316.

(29) Yang, X.; Li, H.; Lu, A.-Y.; Min, S.; Idriss, Z.; Hedhili, M. N.; Huang, K.-W.; Idriss, H.; Li, L.-J. Highly Acid-Durable Carbon Coated $\mathrm{Co}_{3} \mathrm{O}_{4}$ Nanoarrays as Efficient Oxygen Evolution Electrocatalysts. Nano Energy 2016, 25, 42-50.

(30) Costentin, C.; Nocera, D. G. Self-Healing Catalysis in Water. Proc. Natl. Acad. Sci. 2017, 114 (51), 13380-13384.

(31) Surendranath, Y.; Kanan, M. W.; Nocera, D. G. Mechanistic Studies of the Oxygen Evolution Reaction by a CobaltPhosphate Catalyst at Neutral PH. J. Am. Chem. Soc. 2010, 132 (46), 16501-16509.

(32) Frydendal, R.; Paoli, E. A.; Chorkendorff, I.; Rossmeisl, J.; Stephens, I. E. L. Toward an Active and Stable Catalyst for Oxygen Evolution in Acidic Media: Ti-Stabilized $\mathrm{MnO}_{2}$. Adv . Energy Mater. 2015, 5 (22), 1500991.

(33) Zhou, L.; Shinde, A.; Montoya, J. H.; Singh, A.; Gul, S.; Yano, J.; Ye, Y.; Crumlin, E. J.; Richter, M. H.; Cooper, J. K.; et al. Rutile Alloys in the Mn-Sb-O System Stabilize $\mathrm{Mn}^{3+}$ To Enable Oxygen Evolution in Strong Acid. ACS Catal. 2018, 8 (12), 10938-10948

(34) Fabbri, E.; Nachtegaal, M.; Binninger, T.; Cheng, X.; Kim, B. J.; Durst, J.; Bozza, F.; Graule, T.; Schäublin, R.; Wiles, L.; et al. Dynamic Surface Self-Reconstruction Is the Key of Highly Active Perovskite Nano-Electrocatalysts for Water Splitting. Nat. Mater. 2017, 16 (9), 925-931.

(35) Duan, Y.; Sun, S.; Sun, Y.; Xi, S.; Chi, X.; Zhang, Q.; Ren, X.; Wang, J.; Ong, S. J. H.; Du, Y. Mastering Surface Reconstruction of Metastable Spinel Oxides for Better Water Oxidation. Adv. Mater. 2019, 31 (12), 1807898.

(36) McCrory, C. C. L.; Jung, S.; Peters, J. C.; Jaramillo, T. F Benchmarking Heterogeneous Electrocatalysts for the Oxygen Evolution Reaction. J. Am. Chem. Soc. 2013, 135 (45), 1697716987.

(37) Song, F.; Bai, L.; Moysiadou, A.; Lee, S.; Hu, C.; Liardet, L.; $\mathrm{Hu}, \mathrm{X}$. Transition Metal Oxides as Electrocatalysts for the Oxygen Evolution Reaction in Alkaline Solutions: An Application-Inspired Renaissance. J. Am. Chem. Soc. 2018, 140 (25), 7748-7759.

(38) Han, B.; Stoerzinger, K. A.; Tileli, V.; Gamalski, A. D.; Stach, E. A.; Shao-Horn, Y. Nanoscale Structural Oscillations in Perovskite Oxides Induced by Oxygen Evolution. Nat. Mater. 2017, 16 (1), 121.

(39) Jiao, Y.; Zheng, Y.; Jaroniec, M.; Qiao, S. Z. Design of Electrocatalysts for Oxygen-and Hydrogen-Involving Energy Conversion Reactions. Chem. Soc. Rev. 2015, 44 (8), 2060 2086.

(40) Dionigi, F.; Strasser, P. NiFe- Based (Oxy) Hydroxide Catalysts for Oxygen Evolution Reaction in Non- Acidic Electrolytes. Adv. Energy Mater. 2016, 6 (23), 1600621.

(41) Lee, Y.; Suntivich, J.; May, K. J.; Perry, E. E.; Shao-Horn, Y. Synthesis and Activities of Rutile $\mathrm{IrO}_{2}$ and $\mathrm{RuO}_{2}$ Nanoparticles for Oxygen Evolution in Acid and Alkaline Solutions. J. Phys. Chem. Lett. 2012, 3 (3), 399-404.

(42) Geiger, S.; Kasian, O.; Ledendecker, M.; Pizzutilo, E.; Mingers, A. M.; Fu, W. T.; Diaz-Morales, O.; Li, Z.; Oellers, T.; Fruchter, L.; et al. The Stability Number as a Metric for Electrocatalyst Stability Benchmarking. Nat. Catal. 2018, 1 (7), 508-515.

(43) Sanchezcasalongue, H. G.; Ng, M. L.; Kaya, S.; Friebel, D.; Ogasawara, H.; Nilsson, A. InSitu Observation of Surface Species on Iridium Oxide Nanoparticles during the Oxygen Evolution Reaction. Angew. Chemie - Int. Ed. 2014, 53 (28), 7169-7172.

(44) Grimaud, A.; Demortière, A.; Saubanère, M.; Dachraoui, W.; Duchamp, M.; Doublet, M.-L.; Tarascon, J.-M. Activation of Surface Oxygen Sites on an Iridium-Based Model Catalyst for the Oxygen Evolution Reaction. Nat. Energy 2016, 2, 16189.

(45) Nong, H. N.; Reier, T.; Oh, H.-S.; Gliech, M.; Paciok, P.; Vu, T. H. T.; Teschner, D.; Heggen, M.; Petkov, V.; Schlögl, R.; et al. A Unique Oxygen Ligand Environment Facilitates Water Oxidation in Hole-Doped IrNiOx Core-shell Electrocatalysts. Nat. Catal. 2018, 1 (11), 841-851.

(46) Saveleva, V. A.; Wang, L.; Teschner, D.; Jones, T.; Gago, A. S.; 
Friedrich, K. A.; Zafeiratos, S.; Schlögl, R.; Savinova, E. R. Operando Evidence for a Universal Oxygen Evolution Mechanism on Thermal and Electrochemical Iridium Oxides. $J$. Phys. Chem. Lett. 2018, 9 (11), 3154-3160.

(47) Grimaud, A.; May, K. J.; Carlton, C. E.; Lee, Y.-L.; Risch, M. Hong, W. T.; Zhou, J.; Shao-Horn, Y. Double Perovskites as a Family of Highly Active Catalysts for Oxygen Evolution in Alkaline Solution. Nat. Commun. 2013, 4, 2439.

(48) Liu, S.; Luo, H.; Li, Y.; Liu, Q.; Luo, J. L. Structure-Engineered Electrocatalyst Enables Highly Active and Stable Oxygen Evolution Reaction over Layered Perovskite $\mathrm{LaSr}_{3} \mathrm{Co}_{1.5} \mathrm{Fe}_{1.5} \mathrm{O}_{10}$ §. Nano Energy 2017, 40 (June), 115-121.

(49) Xia, W.; Zhou, Q.; Xu, H.; Chen, L.; He, J. Magnetic and Transport Properties of the Double Perovskite $\mathrm{Sr}_{2} \mathrm{FeRuO}_{6}$. Phys. B Condens. Matter 2008, 403 (13-16), 2189-2192.

(50) Forslund, R. P.; Hardin, W. G.; Rong, X.; Abakumov, A. M.; Filimonov, D.; Alexander, C. T.; Mefford, J. T.; Iyer, H.; Kolpak, A. M.; Johnston, K. P.; et al. Exceptional Electrocatalytic Oxygen Evolution via Tunable Charge Transfer Interactions in $\mathrm{La}_{0.5} \mathrm{Sr}_{1.5} \mathrm{Ni}_{1-\mathrm{x}} \mathrm{Fe}_{\mathrm{x}} \mathrm{O}_{4 \pm \delta}$ Ruddlesden-Popper Oxides. Nat. Commun. 2018, 9 (1), 3150.

(51) Chen, Y.; Li, H.; Wang, J.; Du, Y.; Xi, S.; Sun, Y.; Sherburne, M.; Ager, J. W.; Fisher, A. C.; Xu, Z. J. Exceptionally Active Iridium Evolved from a Pseudo-Cubic Perovskite for Oxygen Evolution in Acid. Nat. Commun. 2019, 10 (1), 572.

(52) Lebedev, D.; Povia, M.; Waltar, K.; Abdala, P. M.; Castelli, I. E.; Fabbri, E.; Blanco, M. V; Fedorov, A.; Copéret, C.; Marzari, $\mathrm{N}$; ; et al. Highly Active and Stable Iridium Pyrochlores for Oxygen Evolution Reaction. Chem. Mater. 2017, 29 (12), 51825191.

(53) Yoon, Y.; Yan, B.; Surendranath, Y. Suppressing Ion Transfer Enables Versatile Measurements of Electrochemical Surface Area for Intrinsic Activity Comparisons. J. Am. Chem. Soc. 2018, 140 (7), 2397-2400.

(54) Wei, C.; Sun, S.; Mandler, D.; Wang, X.; Qiao, S. Z.; Xu, Z. J. Approaches for Measuring the Surface Areas of Metal Oxide Electrocatalysts for Determining Their Intrinsic Electrocatalytic Activity. Chem. Soc. Rev. 2019, 48 (9), 2518-2534.

(55) Yagi, S.; Yamada, I.; Tsukasaki, H.; Seno, A.; Murakami, M.; Fujii, H.; Chen, H.; Umezawa, N.; Abe, H.; Nishiyama, N. Covalency-Reinforced Oxygen Evolution Reaction Catalyst. Nat. Commun. 2015, 6, 8249.

(56) Abbott, D. F.; Lebedev, D.; Waltar, K.; Povia, M.; Nachtegaal, M.; Fabbri, E.; Copéret, C.; Schmidt, T. J. Iridium Oxide for the Oxygen Evolution Reaction: Correlation between Particle Size, Morphology, and the Surface Hydroxo Layer from Operando XAS. Chem. Mater. 2016, 28 (18), 6591-6604.

(57) Gao, J.; Xu, C.; Hung, S.; Liu, W.; Cai, W.; Zeng, Z.; Jia, C.; Chen, H. M.; Xiao, H.; Li, J.; et al. Breaking Long-Range Order in Iridium Oxide by Alkali Ion For. J. Am. Chem. Soc. 2019, 141, 3014-3023.

(58) Godínez-Salomón, F.; Albiter, L.; Alia, S. M.; Pivovar, B. S.; Camacho-Forero, L. E.; Balbuena, P. B.; Mendoza-Cruz, R.; Arellano-Jimenez, M. J.; Rhodes, C. P. Self-Supported Hydrous Iridium-Nickel Oxide Two-Dimensional Nanoframes for High Activity Oxygen Evolution Electrocatalysts. ACS Catal. 2018, 8 (11), 10498-10520.

(59) Zhang, R.; Dubouis, N.; Osman, M. Ben; Yin, W.; Sougrati, M. T.; Corte, D. A. D.; Giaume, D.; Grimaud, A. A Dissolution / Precipitation Equilibrium on the Surface of Iridium- Based Perovskites Controls Their Activity as Oxygen Evolution Reaction Catalysts in Acidic Media Communications Angewandte. Angew. Chemie - Int. Ed. 2019, 1-6.

(60) Blakemore, J. D.; Schley, N. D.; Olack, G. W.; Incarvito, C. D.; Brudvig, G. W.; Crabtree, R. H. Anodic Deposition of a Robust Iridium-Based Water-Oxidation Catalyst from Organometallic Precursors. Chem. Sci. 2011, 2 (1), 94-98.

(61) Pearce, P.; Yang, C.; Iadecola, A.; Rodriguez-Carvajal, J.; Rousse, G.; Dedryvère, R.; Abakumov, A. M.; Giaume, D.; Deschamps, M.; Tarascon, J.-M.; et al. Revealing the Reactivity of the Iridium Trioxide Intermediate for the Oxygen Evolution Reaction in Acidic Media. Chem. Mater. 2019, 31 (15), 58455855.

(62) Perez, A. J.; Beer, R.; Lin, Z.; Salager, E.; Taberna, P.; Abakumov, A. M.; Simon, P.; Tarascon, J. Proton Ion Exchange
Reaction in $\mathrm{Li}_{3} \mathrm{IrO}_{4}$ : A Way to New $\mathrm{H}_{3+\mathrm{x}} \mathrm{IrO}_{4}$ Phases Electrochemically Active in Both Aqueous and Nonaqueous Electrolytes. Adv. Energy Mater. 2018, 8 (13), 1702855.

Kasian, O.; Grote, J. P.; Geiger, S.; Cherevko, S.; Mayrhofer, K. J. J. The Common Intermediates of Oxygen Evolution and Dissolution Reactions during Water Electrolysis on Iridium. Angew. Chemie - Int. Ed. 2018, 57 (9), 2488-2491.

Berthelot, R.; Carlier, D.; Delmas, C. Electrochemical Investigation of the $\mathrm{P} 2-\mathrm{Na}_{\mathrm{x}} \mathrm{CoO}_{2}$ Phase Diagram. Nat. Mater. 2010, 10, 74.

(65) Mariyappan, S.; Abakumov, A.; Foix, D.; Rousse, G.; Ramesha, K.; Saubanere, M.; Doublet, M.-L.; Vezin, H.; C P, L.; Annigere, P.; et al. Origin of Voltage Decay in High-Capacity Layered Oxide Electrodes. Nat. Mater. 2015, 14, 230.

(66) Sheng, W.; Gasteiger, H. A.; Shao-Horn, Y. Hydrogen Oxidation and Evolution Reaction Kinetics on Platinum: Acid vs Alkaline Electrolytes. J. Electrochem. Soc. 2010, 157 (11), B1529.

(67) Subbaraman, R.; Tripkovic, D.; Strmcnik, D.; Chang, K.-C.; Uchimura, M.; Paulikas, A. P.; Stamenkovic, V.; Markovic, N. M. Enhancing Hydrogen Evolution Activity in Water Splitting by Tailoring $\mathrm{Li}^{+}-\mathrm{Ni}(\mathrm{OH})_{2}$-Pt Interfaces. Science (80-. ). 2011, 334 (6060), 1256-1260.

(68) Strmcnik, D.; Uchimura, M.; Wang, C.; Subbaraman, R.; Danilovic, N.; van der Vliet, D.; Paulikas, A. P.; Stamenkovic, V. R.; Markovic, N. M. Improving the Hydrogen Oxidation Reaction Rate by Promotion of Hydroxyl Adsorption. Nat. Chem. 2013, 5 (4), 300-306.

(69) Gileadi, E. Physical Electrochemistry; Wiley-VCH Verlag GmbH \& Co. KGaA, 2011.

(70) Shinagawa, T.; Garcia-Esparza, A. T.; Takanabe, K. Insight on Tafel Slopes from a Microkinetic Analysis of Aqueous Electrocatalysis for Energy Conversion. Sci. Rep. 2015, 5, 13801.

(71) Zheng, Y.; Jiao, Y.; Vasileff, A.; Qiao, S.-Z. The Hydrogen Evolution Reaction in Alkaline Solution: From Theory, Single Crystal Models, to Practical Electrocatalysts. Angew. Chemie Int. Ed. 2018, 57 (26), 7568-7579.

(72) Zeradjanin, A. R.; Vimalanandan, A.; Polymeros, G.; Topalov, A. A.; Mayrhofer, K. J. J.; Rohwerder, M. Balanced Work Function as a Driver for Facile Hydrogen Evolution Reaction Comprehension and Experimental Assessment of Interfacial Catalytic Descriptor. Phys. Chem. Chem. Phys. 2017, 19 (26), 17019-17027.

(73) Rossmeisl, J.; Chan, K.; Skúlason, E.; Björketun, M. E.; Tripkovic, V. On the PH Dependence of Electrochemical Proton Transfer Barriers. Catal. Today 2016, 262, 36-40.

(74) Grimaud, A.; Demortière, A.; Saubanere, M.; Dachraoui, W.; Duchamp, M.; Doublet, M.-L.; Tarascon, J.-M. Activation of Surface Oxygen Sites on an Iridium-Based Model Catalyst for the Oxygen Evolution Reaction. Nat. Energy 2017, 2 (1), 16189. Grimaud, A.; Diaz-Morales, O.; Han, B.; Hong, W. T.; Lee, Y.L.; Giordano, L.; Stoerzinger, K. A.; Koper, M. T. M.; ShaoHorn, Y. Activating Lattice Oxygen Redox Reactions in Metal Oxides to Catalyse Oxygen Evolution. Nat. Chem. 2017, 9 (5), 457.

(76) Bockris, J. O.; Otagawa, T. Mechanism of Oxygen Evolution on Perovskites. J. Phys. Chem. 2002, 87 (15), 2960-2971.

(77) Huang, B.; Muy, S.; Feng, S.; Katayama, Y.; Lu, Y.-C.; Chen, G.; Shao-Horn, Y. Non-Covalent Interactions in Electrochemical Reactions and Implications in Clean Energy Applications. Phys. Chem. Chem. Phys. 2018, 20 (23), 1568015686.

(78) Anderson, A. B.; Roques, J.; Mukerjee, S.; Murthi, V. S.; Markovic, N. M.; Stamenkovic, V. Activation Energies for Oxygen Reduction on Platinum Alloys: Theory and Experiment. J. Phys. Chem. B 2005, 109 (3), 1198-1203.

(79) Zeradjanin, A. R. Is a Major Breakthrough in the Oxygen Electrocatalysis Possible? Curr. Opin. Electrochem. 2018, 9, 214-223.

(80) Shinagawa, T.; Takanabe, K. New Insight into the Hydrogen Evolution Reaction under Buffered Near-Neutral PH Conditions: Enthalpy and Entropy of Activation. J. Phys. Chem. C 2016, 120 (42), 24187-24196.

(81) Bligaard, T.; Nørskov, J. K.; Dahl, S.; Matthiesen, J.; 
Christensen, C. H.; Sehested, J. The Brønsted-Evans-Polanyi Relation and the Volcano Curve in Heterogeneous Catalysis. $J$. Catal. 2004, 224 (1), 206-217.

Koper, M. T. M. Thermodynamic Theory of Multi-Electron Transfer Reactions: Implications for Electrocatalysis. $J$. Electroanal. Chem. 2011, 660 (2), 254-260.

(83) Bockris, J. O.; Otagawa, T. Mechanism of Oxygen Evolution on Perovskites. J. Phys. Chem. 1983, 87 (15), 2960-2971.

(84) Yang, C.; Batuk, M.; Jacquet, Q.; Rousse, G.; Yin, W.; Zhang, L.; Hadermann, J.; Abakumov, A. M.; Cibin, G.; Chadwick, A. Revealing PH-Dependent Activities and Surface Instabilities for Ni-Based Electrocatalysts during the Oxygen Evolution Reaction. ACS Energy Lett. 2018, 3 (12), 2884-2890.

(85) Geissler, P. L. Autoionization in Liquid Water. Science (80-. ). 2001, 291 (5511), 2121-2124.

(86) Muñoz-Santiburcio, D.; Marx, D. Nanoconfinement in Slit Pores Enhances Water Self-Dissociation. Phys. Rev. Lett. 2017, 119 (5), 056002.

(87) Moqadam, M.; Lervik, A.; Riccardi, E.; Venkatraman, V.; Ka, B.; van Erp, T. S. Local Initiation Conditions for Water Autoionization. Proc. Natl. Acad. Sci. 2018, 115 (20), E4569E4576.

(88) Kuo, D.-Y.; Kawasaki, J. K.; Nelson, J. N.; Kloppenburg, J.; Hautier, G.; Shen, K. M.; Schlom, D. G.; Suntivich, J. Influence of Surface Adsorption on the Oxygen Evolution Reaction on IrO2 (110). J. Am. Chem. Soc. 2017, 139 (9), 3473-3479.

(89) Yang, C.; Fontaine, O.; Tarascon, J.; Grimaud, A. Chemical Recognition of Active Oxygen Species on the Surface of Oxygen Evolution Reaction Electrocatalysts. Angew. Chemie 2017, 129 (30), 8778-8782.

(90) Garcia, A. C.; Touzalin, T.; Nieuwland, C.; Perini, N.; Koper, M. T. M. Enhancement of Oxygen Evolution Activity of $\mathrm{NiOOH}$ by Electrolyte Alkali Cations. Angew. Chemie Int. Ed. 2019, (ja), DOI: 10.1002/anie.201905501.

(91) Yang, C.; Laberty-Robert, C.; Batuk, D.; Cibin, G.; Chadwick, A. V; Pimenta, V.; Yin, W.; Zhang, L.; Tarascon, J.-M.; Grimaud, A. Phosphate Ion Functionalization of Perovskite Surfaces for Enhanced Oxygen Evolution Reaction. J. Phys. Chem. Lett. 2017, 8 (15), 3466-3472.
Dubouis, N* Serva, A: Salager, E; Deschamps, M; Salanne, M.; Grimaud, A. The Fate of Water at the Electrochemical Interfaces: Electrochemical Behavior of Free Water Versus Coordinating Water. J. Phys. Chem. Lett. 2018, 9 (23), 66836688 .

(93) Chen, G.; Zhu, Y.; Chen, H. M.; Hu, Z.; Hung, S.-F.; Ma, N.; Dai, J.; Lin, H.-J.; Chen, C.-T.; Zhou, W.; et al. An Amorphous Nickel-Iron-Based Electrocatalyst with Unusual Local Structures for Ultrafast Oxygen Evolution Reaction. Adv. Mater. 2019, 31 (28), 1900883.

(94) Chen, G.; Hu, Z.; Zhu, Y.; Gu, B.; Zhong, Y.; Lin, H.-J.; Chen, C.-T.; Zhou, W.; Shao, Z. A Universal Strategy to Design Superior Water-Splitting Electrocatalysts Based on Fast In Situ Reconstruction of Amorphous Nanofilm Precursors. Adv. Mater. 2018, 30 (43), 1804333.

(95) Zhu, Y.; Zhou, W.; Sunarso, J.; Zhong, Y.; Shao, Z. Phosphorus-Doped Perovskite Oxide as Highly Efficient Water Oxidation Electrocatalyst in Alkaline Solution. Adv. Funct. Mater. 2016, 26 (32), 5862-5872.

(96) Gutowski, K. E.; Broker, G. A.; Willauer, H. D.; Huddleston, J. G.; Swatloski, R. P.; Holbrey, J. D.; Rogers, R. D. Controlling the Aqueous Miscibility of Ionic Liquids: Aqueous Biphasic Systems of Water-Miscible Ionic Liquids and Water-Structuring Salts for Recycle, Metathesis, and Separations. J. Am. Chem. Soc. 2003, 125 (22), 6632-6633.

(97) Bridges, N. J.; Gutowski, K. E.; Rogers, R. D. Investigation of Aqueous Biphasic Systems Formed from Solutions of Chaotropic Salts with Kosmotropic Salts (Salt-salt ABS). Green Chem. 2007, 9 (2), 177-183.

(98) Marcus, Y. Effect of Ions on the Structure of Water: Structure Making and Breaking. Chem. Rev. 2009, 109 (3), 1346-1370.

(99) Dubouis, N.; Park, C.; Deschamps, M.; Abdelghani-Idrissi, S.; Kanduč, M.; Colin, A.; Salanne, M.; Dzubiella, J.; Grimaud, A.; Rotenberg, B. Chasing Aqueous Biphasic Systems from Simple Salts by Exploring the LiTFSI/LiCl/H2O Phase Diagram. ACS Cent. Sci. 2019, 5 (4), 640-643.

\section{ToC}

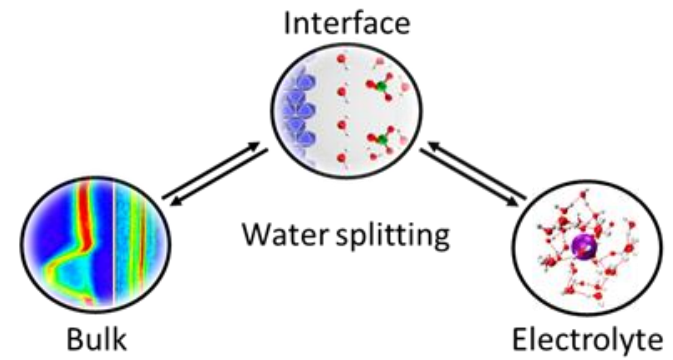

Ronghuan Zhang is currently a postdoctoral researcher in the Solid-State Chemistry and Energy lab under Prof. Jean-Marie Tarascon and Dr. Alexis Grimaud. She received her Ph.D. degree in inorganic chemistry from the University of Oxford under the supervision of Prof. Micheal A. Hayward. Her recent research focuses on the exploration of novel Ir-based catalysts for water splitting. 


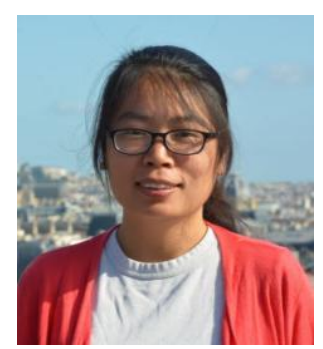

Paul E. Pearce is currently a Ph.D. student in the Solid-State Chemistry and energy laboratory at Collège de France in Paris, France, under the supervision of Jean-Marie Tarascon and Gwenaëlle Rousse. His work is dedicated to the study of the charge compensation mechanism by lattice oxygen during the insertion of alkali ions and protons in iridates for battery and water splitting applications by means of diffraction and spectroscopic techniques both ex situ and operando.

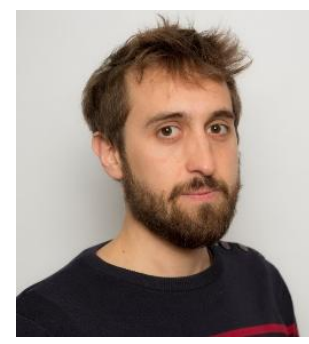

Yan Duan received her B.Eng degree from Nanyang Technologivcal University. She is currently a joint Ph.D. candidate in materials engineering at Nanyang Technologivcal University and Collège de France under the supervision of Assoc. Prof. Zhichuan J. Xu and Dr. Alexis Grimaud. Her research focus on understanding the reaction mechanism of transition metal oxide as oxygen electrocatalysis.

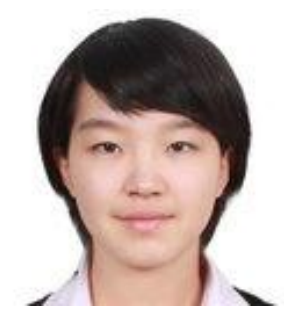

Nicolas Dubouis holds an MSc. degree in Chemistry from the École normale supérieure (Paris). He is currently a Ph.D. candidate in physical chemistry at Collège de France and Sorbonne Université, working in the Solid-State Chemistry and Energy laboratory under Prof. Jean-Marie Tarascon and Dr. Alexis Grimaud, studying how interfacial water environment impacts its electrochemical reactivity.

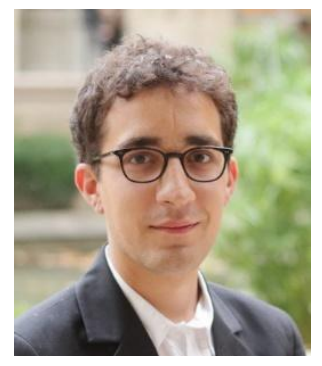


Thomas Marchandier received his MSc. degree from the Ecole normale Supérieur Paris-Saclay. He is currently a Ph.D. student at the Collège de France under the supervision of Professor Jean-Marie Tarascon. His work deals with the design of new materials for energy applications, with particular emphasis on low temperatures and solution-based synthesis.

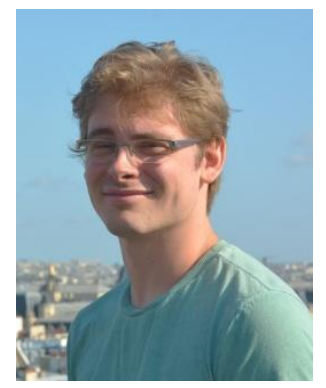

Alexis Grimaud is a CNRS associate researcher at Collège de France, Paris. He received his $\mathrm{PhD}$ in materials science from the University of Bordeaux in 2011 before to work as postdoctoral associate at Massachusetts Institute of Technology (MIT). His research efforts are paid toward the understanding of electrochemical interfaces that are relevant to energy storage and conversion devices with a special emphasis on transition metal oxides electronic properties and aqueous electrolytes solvation structure.

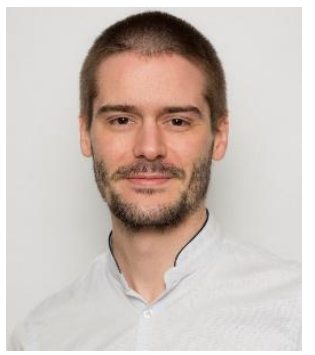

